\title{
A Numerical Study on Rapid Intensification of Typhoon Vicente (2012) in the South China Sea. Part II: Roles of Inner-Core Processes
}

\author{
XIAOMIN CHEN \\ Key Laboratory for Mesoscale Severe Weather/Ministry of Education, and School of Atmospheric Sciences, \\ Nanjing University, Nanjing, China, and International Pacific Research Center, and Department of Atmospheric Sciences, \\ School of Ocean and Earth Science and Technology, University of Hawai' $i$ at Mānoa, Honolulu, Hawaii \\ YUQING WANG \\ International Pacific Research Center, and Department of Atmospheric Sciences, School of Ocean and \\ Earth Science and Technology, University of Hawai'i at Mānoa, Honolulu, Hawaii

\section{JUAN FANG} \\ Key Laboratory for Mesoscale Severe Weather/Ministry of Education, and School of Atmospheric Sciences, \\ Nanjing University, Nanjing, China

\section{MiNG XUE} \\ Key Laboratory for Mesoscale Severe Weather/Ministry of Education, and School of Atmospheric Sciences, \\ Nanjing University, Nanjing, China, and Center for Analysis and Prediction of Storms, and School of Meteorology, \\ University of Oklahoma, Norman, Oklahoma
}

(Manuscript received 25 April 2017, in final form 28 October 2017)

\begin{abstract}
In Part I of this study, the role of environmental monsoon flow in the onset of rapid intensification (RI) of Typhoon Vicente (2012) was discussed. In this Part II, key inner-core processes that effectively resist environmental vertical wind shear during RI onset are investigated. The convective precipitation shield (CPS) embedded in the downshear convergence zone plays a vital role in preconditioning the tropical cyclone (TC) vortex before RI. The CPS induces a mesoscale positive vorticity band (PVB) characterized by vortical hot tower structures upstream and shallower structures $(\sim 4 \mathrm{~km})$ downstream. Multiple mesovortices form successively along the PVB and are detached from the PVB at its downstream end, rotating cyclonically around the TC center. The sufficient amount of vorticity anomalies in the PVB facilitates the upscale growth of a mesovortex into a reformed inner vortex, which eventually replaces the parent TC vortex (i.e., downshear reformation), leading to RI onset. The timing of downshear reformation is closely related to the gradually enhancing convective activity in the CPS, which is likely triggered/enhanced by increased surface heat fluxes in the downshear-left quadrant. Results from vorticity budget analyses suggest that convection in the CPS contributes to the vertical development of the tilted reformed inner vortex largely through tilting horizontal vorticity and advecting vorticity upward. The enhanced midlevel inner vortex precesses more quickly into the upshear flank and is concurrently advected toward the low-level inner vortex, resulting in vertical alignment of the reformed inner vortex and parent TC vortex at the end of downshear reformation.
\end{abstract}

\section{Introduction}

Rapid intensification (RI) of tropical cyclones (TCs) is a special phase of intense TCs and remains challenging in operational forecasts (Rappaport et al. 2012; DeMaria

Corresponding author: Prof. Yuqing Wang, yuqing@hawaii.edu et al. 2014). One of the most important conundrums in RI forecasts relates to the effect of environmental vertical wind shear (VWS). Environmental VWS has been found hostile to TC intensification in many observational and modeling studies (Gray 1968; Frank and Ritchie 2001; Black et al. 2002; Wong and Chan 2004; Zeng et al. 2007, 2008; Tang and Emanuel 2010; Wang et al. 2015). 
TCs experiencing RI are often embedded in an environment with weak VWS (Kaplan and DeMaria 2003; Kaplan et al. 2010; Shu et al. 2012; Chen et al. 2015). From the viewpoint of a TC Carnot engine (e.g., Emanuel 1986, 1988), environmental VWS can reduce the efficiency of the energy cycle by ventilating the upper-level warm core (Gray 1968), transporting high-entropy air in the upper part of the vortex outward (Frank and Ritchie 2001), diluting the high-entropy air in the eyewall in the midtroposphere (Simpson and Riehl 1958; Cram et al. 2007), inducing strong downdrafts and intrusion of low-entropy air in the boundary layer inflow (Riemer et al. 2010; Ge et al. 2013), or by transporting boundary layer highentropy air upward outside the eyewall by shear-induced convection and thereby reducing the radial gradient of entropy across the eyewall (Gu et al. 2015). These ventilation processes can interrupt TC intensification or even cause TC weakening.

Besides the thermodynamic effects summarized above, environmental VWS can alter TC structure and further modulate TC intensity. Dynamically, environmental VWS can tilt a vertically aligned TC vortex to downshear or downshear left, exciting a convective precipitation shield (CPS) therein. The shear-induced asymmetries can often induce significant eddy mixing of angular momentum across the eyewall and weaken the TC (Jones 1995; DeMaria 1996; Wang and Holland 1996; Wu and Braun 2004; Reasor et al. 2004). Once tilted, a TC vortex often has a shallower, less-organized secondary circulation, which is less efficient in converging the absolute angular momentum surface inward to spin up tangential wind in the inner core (Shapiro and Willoughby 1982; DeMaria 1996; Riemer et al. 2010).

However, recent observational studies have shown that some tropical storms are capable of intensifying rapidly in relatively strong environmental VWS $\left(>10 \mathrm{~m} \mathrm{~s}^{-1}\right)$ or moderate VWS $\left(7-10 \mathrm{~m} \mathrm{~s}^{-1}\right)$. Examples of the former include Hurricane Gabrielle (2001) (Molinari et al. 2006; Molinari and Vollaro 2010; Nguyen and Molinari 2015) and of the latter include Hurricane Earl (2010) (Rogers et al. 2015; Stevenson et al. 2014; Susca-Lopata et al. 2015). In both cases, RI onset (i.e., the period leading to RI) exhibited a similar phenomenon: as the downshear CPS rotates cyclonically into the upshear flank, a notable reduction of vortex tilt (i.e., vertical alignment) immediately follows. As the vortex tilt becomes small, the importance of the radial location of the maximum diabatic heating increases. In particular, maximum diabatic heating located preferentially inside the radius of maximum wind (RMW) is favorable for TC intensification (Shapiro and Willoughby 1982; Nolan et al. 2007; Pendegrass and Willoughby 2009; Rogers et al. 2013), since diabatic heating is more efficiently converted to net warming in the region of high inertial stability (Schubert and Hack 1982; Vigh and Schubert 2009). Moreover, vertical alignment in environmental VWS (i.e., resilience) can suppress the ventilation effect and shear-induced eddies (e.g., Reasor et al. 2004; Reasor and Eastin 2012). Therefore, vertical alignment is an effective inner-core process to lessen the adverse effects of environmental VWS on TC intensification.

Previous studies have also pointed out the close relationship between the CPS and vertical alignment (e.g., Rappin and Nolan 2012; Zhang and Tao 2013; Stevenson et al. 2014; Rogers et al. 2015; Onderlinde and Nolan 2016; Munsell et al. 2017), though the influence of the CPS on vertical alignment is not yet fully understood. One plausible argument is that the rotation of CPS is an indicator of the precession of the midlevel vortex relative to the low-level vortex, and if the midlevel vortex precesses into the upshear flank, the environmental VWS itself can contribute to vertical alignment. It has also been argued that the CPS contributes to vertical alignment via other, albeit not necessarily mutually exclusive, dynamical mechanisms. First, it can reduce the vortex tilt by inducing an inner-core VWS counteraligned to the environmental VWS (Flatau et al. 1994; Wang and Holland 1996; Zhang and Kieu 2006; Xu and Wang 2013). Second, diabatic heating can help reduce the tilt mode during precession by enhancing the damping of vortex Rossby waves (Reasor et al. 2004). Third, the convergence associated with the CPS concentrates the disorganized potential vorticity (PV) anomalies into a central core, thereby aligning low- and midlevel PV structures (Tory et al. 2006), although this mechanism is in the context of TC genesis.

The last mechanism, termed as "downshear reformation" (Molinari et al. 2004, 2006), involves the byproduct of diabatic heating and the associated innercore dynamical processes. In the simulation of a downshear reformation case [i.e., Hurricane Gabrielle (2001)], Nguyen and Molinari (2015) argued that convective activity in the downshear flank produces a nearly upright mesovortex (i.e., the reformed inner vortex) in the tilted parent TC vortex via the stretching effect, and the reformed inner vortex axisymmetrizes the weak parent TC vortex, leading to reduced vortex tilt and intensification of the TC. However, it is unclear why the mesovortex can resist the strong differential advection of the environmental VWS and remain vertically coherent. In addition, given multiple convective cells being generated in the downshear precipitation shield, the key mechanism that determines the formation of the dominant mesovortex compared with the other companions remains enigmatic.

Typhoon Vicente (2012) started its RI at tropical storm intensity under moderate environmental VWS during the summer monsoon over the South China Sea 
(SCS). Chen et al. (2015) pointed out that TCs in the SCS have the least chance of experiencing RI during the summer monsoon, primarily owing to the stronger VWS compared with that during other seasons. In Chen et al. (2017, hereafter Part I), we documented the evolution of Typhoon Vicente and discussed the spinup mechanisms of the RI onset and axisymmetric intensification stages, as well as the environmental contributions to RI onset based on a successful simulation initialized with the European Centre for Medium-Range Weather Forecasts interim reanalysis (ERA-Interim) data. It was shown that the decrease in environmental VWS during $\mathrm{RI}$ onset is closely connected to the enhanced downshear convective activity and the associated upper-tropospheric convective ridging.

Here, the same simulation dataset is further analyzed to gain insights into the interactions between environmental VWS and the TC vortex and the related innercore dynamical processes during RI onset. In particular, an examination of the simulation results reveals that Vicente underwent downshear reformation during RI onset. Given this, we hope to clarify some of the unresolved questions related to downshear reformation and advance our understanding of TC resilience in the sheared environment. Questions to be addressed include the following: (i) How do the convective activity in the downshear precipitation shield contribute to the growth and vertical development of the reformed inner vortex? (ii) What is the key mechanism that determines the timing of downshear reformation? and (iii) How does the reformed inner vortex withstand the imposed VWS, remain vertically aligned, and impact the TCscale vortex alignment?

The remainder of the paper is organized as follows. Section 2 provides an overview of RI onset in Typhoon Vicente. The vorticity evolution associated with the downshear convective precipitation shield is discussed in section 3. Details of the downshear reformation processes are analyzed in section 4. Finally, conclusions with additional discussions are given in section 5 .

\section{Overview of RI onset in Typhoon Vicente}

Following Part I, the RI onset stage of Vicente is defined as the period from 1200 UTC 22 July to 0200 UTC 23 July, just prior to the subsequent axisymmetric RI period. During RI onset, the simulated maximum 10-m wind gradually intensifies while oscillating significantly (Fig. 1a), reflecting the convective activity in the inner-core region. The minimum sea level pressure (SLP) starts to drop quickly around 1700 UTC 22 July, concurrent with the appearance of the surface wind "bump" (Fig. 1a). This reflects the formation of an
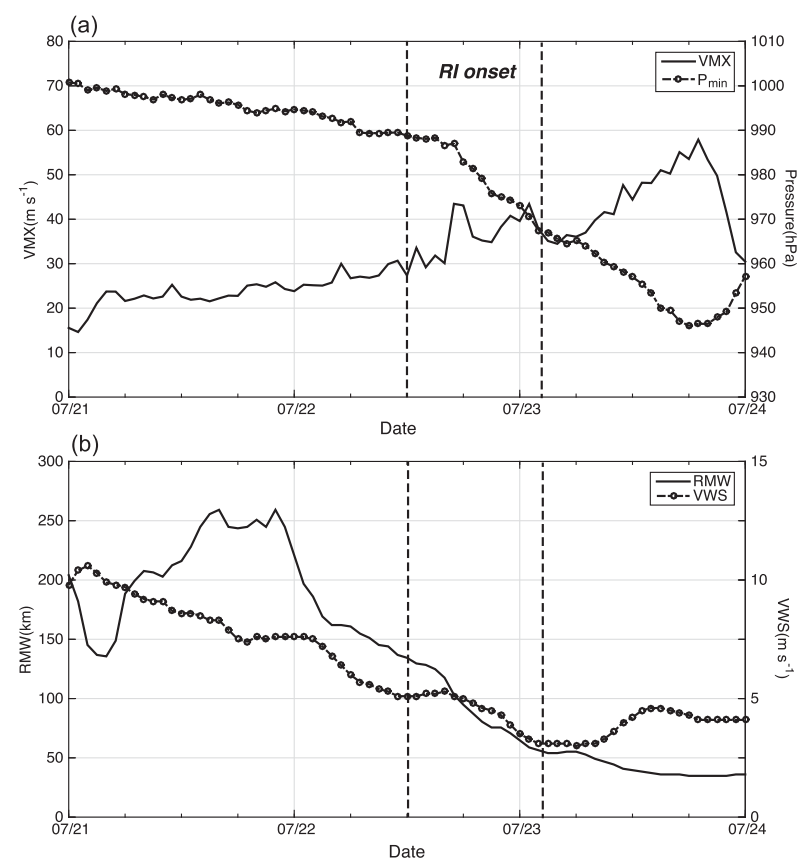

FIG. 1. (a) Time series of the simulated minimum SLP (hPa) and maximum $10-\mathrm{m}$ wind speed $\left(\mathrm{m} \mathrm{s}^{-1}\right)$ from 21 to $24 \mathrm{Jul}$. (b) As in (a), but for the simulated magnitude of the 300-850-hPa environmental VWS $\left(\mathrm{m} \mathrm{s}^{-1}\right)$ and RMW $(\mathrm{km})$ of the surface primary circulation. The $300-850-\mathrm{hPa}$ environmental VWS is calculated within the $300-800-\mathrm{km}$ radii from the surface storm center. The two vertical dash lines indicate the beginning and ending time of RI onset in this study.

intense mesovortex. The minimum SLP subsequently decreases steadily from $988 \mathrm{hPa}$ at 1700 UTC 22 July to $967 \mathrm{hPa}$ at $0200 \mathrm{UTC} 23 \mathrm{July}$ (Fig. 1a). Meanwhile, the 300-850-hPa environmental VWS decreases from 5 to $3 \mathrm{~m} \mathrm{~s}^{-1}$ over the same period. As noted in Part I, the RI onset is also characterized by rapid contraction of the RMW (Fig. 1b). By 0200 UTC 23 July, the RMW is reduced to $\sim 50 \mathrm{~km}$, half its value at 1800 UTC 22 July.

Given these intriguing behaviors during RI onset, it is desirable to further examine the TC structure evolution during the same period. Figure 2 shows passive microwave images of $91-\mathrm{GHz}$ polarization-corrected temperatures (PCT) and simulated layer-maximum ice-phased mixing ratio (including graupel, ice, and snow) within the 8-10-km height range at two selected times for comparison. Note that $91-\mathrm{GHz}$ microwave channel shows the information of ice scattering generally at $8 \mathrm{~km}$ or above, which is indicative of deep convection. The simulation results (Figs. 2c,d) compare well with the microwave images (Figs. 2a,b) in the inner-core region, despite a 2-3-h lag in the simulation. In particular, the model captures the storm structure evolution during RI onset: that is, the downshear CPS, represented by the high values of ice-phased mixing 
(a)
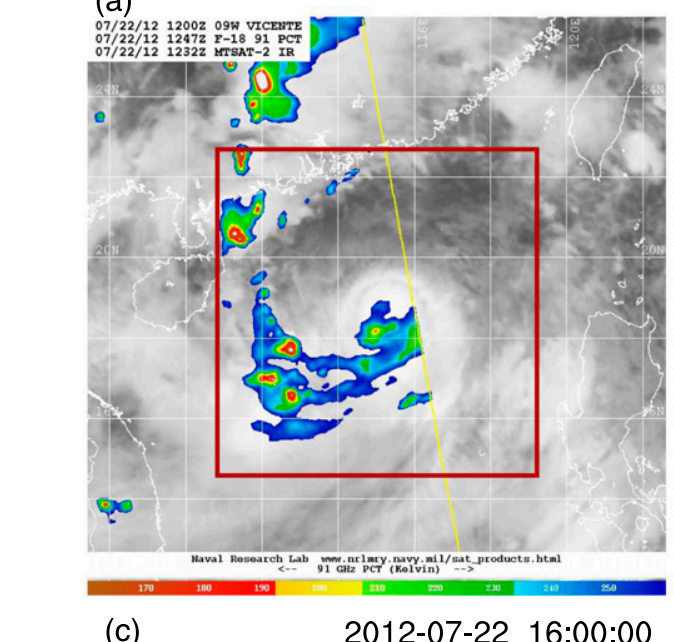

(b)

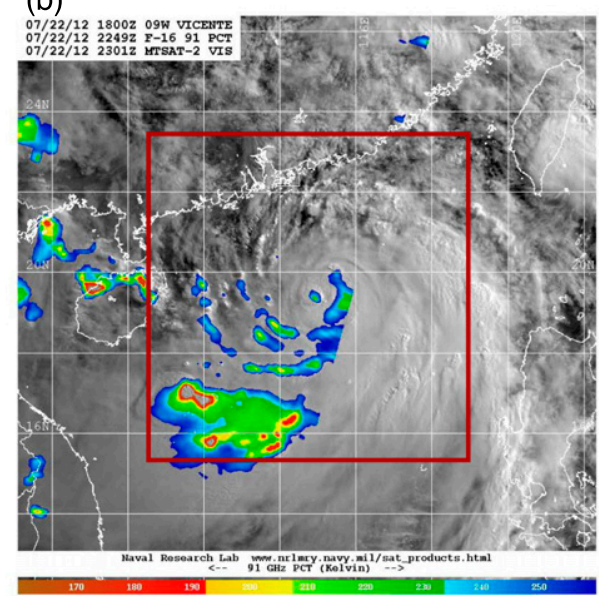

(d) 2012-07-23_01:00:00
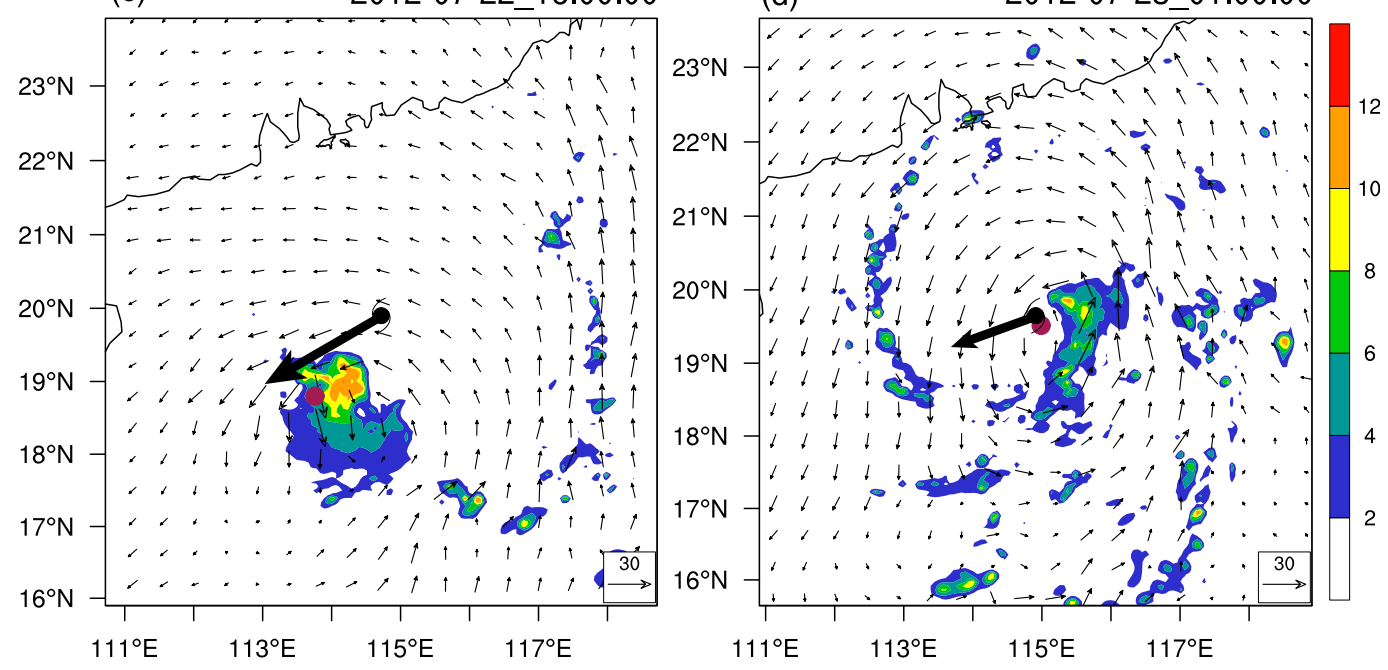

FIG. 2. (top) The 91-GHz PCT satellite microwave images (K) at (a) 1300 and (b) 2300 UTC 22 Jul and (bottom) the simulated layer-max ice-phased mixing ratio within the $8-10-\mathrm{km}$ height range $\left(\mathrm{g} \mathrm{kg}^{-1}\right)$ and the $300-\mathrm{hPa}$ wind vectors (reference vector: $30 \mathrm{~m} \mathrm{~s}^{-1}$ ) at (c) 1600 UTC 22 Jul and (d) 0100 UTC 23 Jul. The black hurricane symbol (red dot) is the surface TC center (the 300-hPa TC center). The magnitudes of 300-850-hPa environmental VWS (black arrow starts from the surface TC center) in (c) and (d) are 5.3 and $3.1 \mathrm{~m} \mathrm{~s}^{-1}$, respectively. The microwave images were downloaded from the Navy Research Laboratory website. The red boxes in (a) and (b) represent the same area shown in (c) and (d).

ratio (Figs. 2c,d), rotates into the upshear flank as a complete eyewall forms. Consistent with previous studies (e.g., Rappin and Nolan 2012; Zhang and Tao 2013), the 300-hPa TC center resides over the downshear CPS (Fig. 2c). The TC center at a given pressure (height) level is defined as the geopotential height (pressure) centroid $(\bar{x}, \bar{y})$ following Nguyen et al. (2014):

$$
\bar{x}=\frac{\iint_{A}\left(P_{i}^{\prime} x\right) d x d y}{\iint_{A} P_{i}^{\prime} d x d y}, \quad \bar{y}=\frac{\iint_{A}\left(P_{i}^{\prime} y\right) d x d y}{\iint_{A} P_{i}^{\prime} d x d y},
$$

$$
P_{i}^{\prime}=P_{\text {env }}-P_{i},
$$

where $P_{i}^{\prime}$ is the geopotential height (pressure) deficit, calculated by subtracting the geopotential height (pressure) at a grid point from the environmental geopotential height (pressure) averaged within a 500-km-radius circle. The area $A$ is taken as a circle with radius $120 \mathrm{~km}$.

The vortex tilt in the $300-850-\mathrm{hPa}$ layer decreases dramatically from $\sim 150 \mathrm{~km}$ at 1600 UTC 22 July to $\sim 30 \mathrm{~km}$ at 010023 July as the CPS rotates into the upshear side (Figs. 2c,d). During the same period, the 300-hPa cyclonic circulation intensifies and exhibits a much more axisymmetric structure. Based on the above analysis, the downshear CPS is related intimately to the 

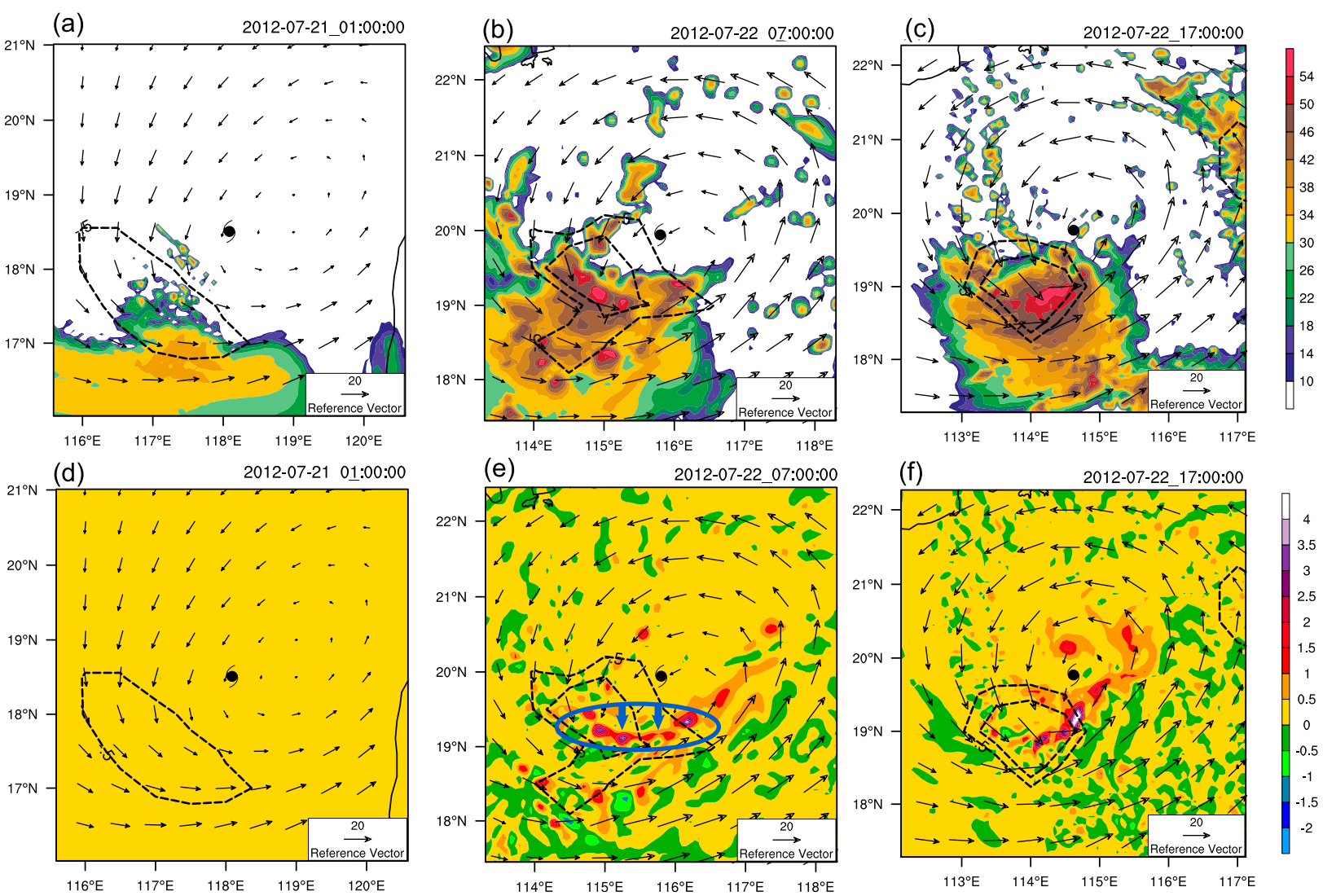

(e)

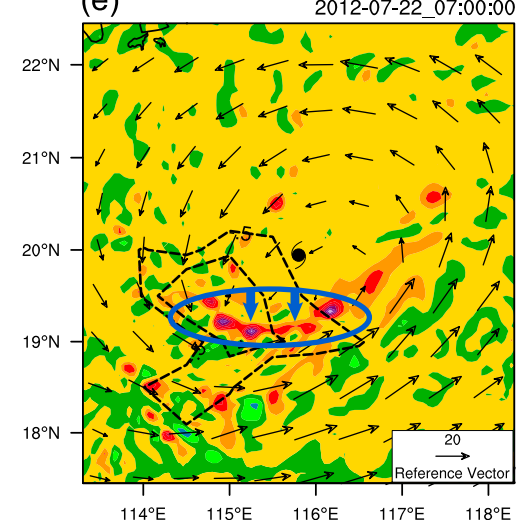

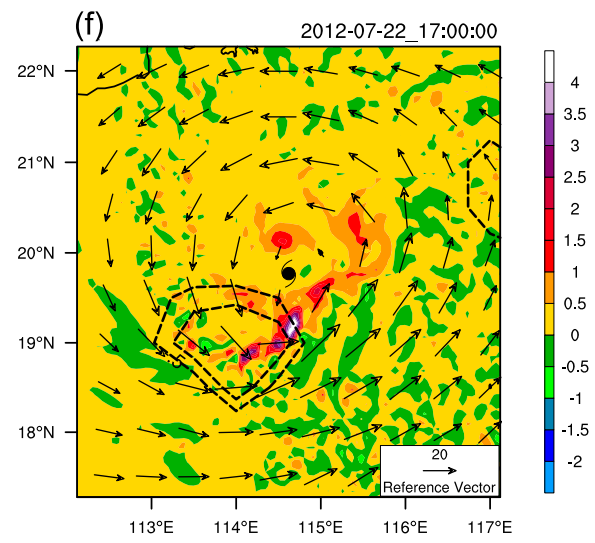

FIG. 3. (top) The simulated composite radar reflectivity (shading; dBZ), the 850-hPa background horizontal convergence (dashed contours with values of $-2.0,-1.0,-0.5 \times 10^{-4} \mathrm{~s}^{-1}$ ), and storm-relative winds (vectors) at (a) $0100 \mathrm{UTC} 21 \mathrm{Jul}$, (b) $0700 \mathrm{UTC} 22 \mathrm{Jul}$, and (c) 1700 UTC 22 Jul. (d)-(f) The corresponding 850-hPa relative vorticity (shading; $10^{-3} \mathrm{~s}^{-1}$ ) and the 850-hPa horizontal convergence as in (a)-(c), respectively. The background horizontal convergence is computed with the coarser data resolution of $0.5^{\circ} \times 0.5^{\circ}$ that is interpolated from the outermost model domain with a horizontal resolution of $18 \mathrm{~km}$. The black hurricane symbol denotes the surface TC center. The blue ellipse and arrows in (e) mark the position of PVB for an example.

reduction in vortex tilt. The specific role of the downshear CPS in the vertical vortex alignment will be a focus of the following analysis. We will first analyze the formation then the subsequent evolution of the downshear CPS as well as the associated dynamical processes in the next section.

\section{Vorticity evolution in the downshear CPS}

A localized downshear convergence zone appears at the beginning of the model simulation (e.g., 0100 UTC 21 July; Fig. 3a). Two factors can explain its formation. First, the confluence between the southwesterly monsoon flow and the northerly winds to the west of the TC center induces a narrow convergence zone to the south of the TC center. Second, as the TC circulation gradually intensifies during its westward movement into the SCS [i.e., as it upgraded to a tropical depression according to the best-track dataset from Joint Typhoon Warning Center (JTWC)], the enhanced differential vorticity advection by the steady thermal wind ${ }^{1}$ (i.e., environmental VWS; $\sim 10.5 \mathrm{~m} \mathrm{~s}^{-1}$ ) forces stronger vertical motion and thus enhanced low-level convergence on the downshear side according to quasigeostrophic theory (Bracken and Bosart 2000; Fischer et al. 2017), numerical simulations (e.g., Jones 1995; Wang and Holland 1996), and observational studies (e.g., Reasor et al. 2009, 2013; DeHart et al. 2014). By 0600 UTC 21 July, the differential vorticity advection by thermal wind is as large as $8 \times 10^{-4} \mathrm{~m} \mathrm{~s}^{-2}$. Afterward, it gradually decreases until 0000 UTC 22 July, owing to the reduction of environmental VWS (not shown). A

\footnotetext{
${ }^{1}$ In a simplified version of the Sutcliffe-Trenberth form of the quasigeostrophic omega equation (Bracken and Bosart 2000), the differential vorticity advection by thermal wind is defined as $V_{T} \cdot \nabla \zeta_{\mathrm{UL}}$, where $V_{T}$ is the $300-850$-hPa environmental VWS and $\zeta_{\mathrm{UL}}$ is the $300-\mathrm{hPa}$ mean relative vorticity averaged within the $300-\mathrm{km}$ radius from the surface TC center.
} 
(a)

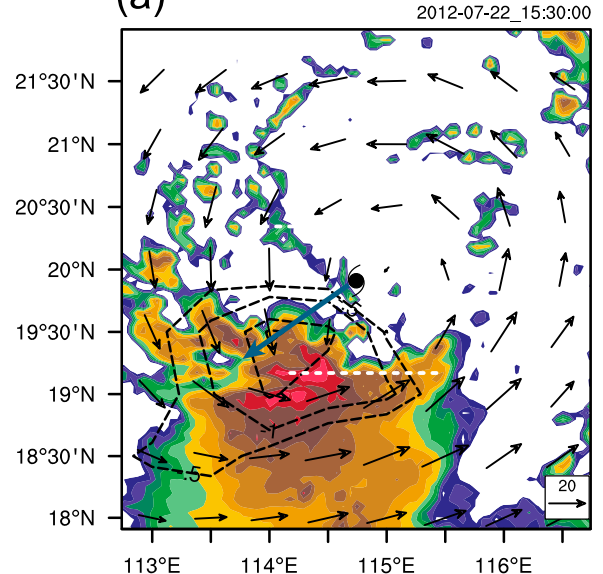

(c)

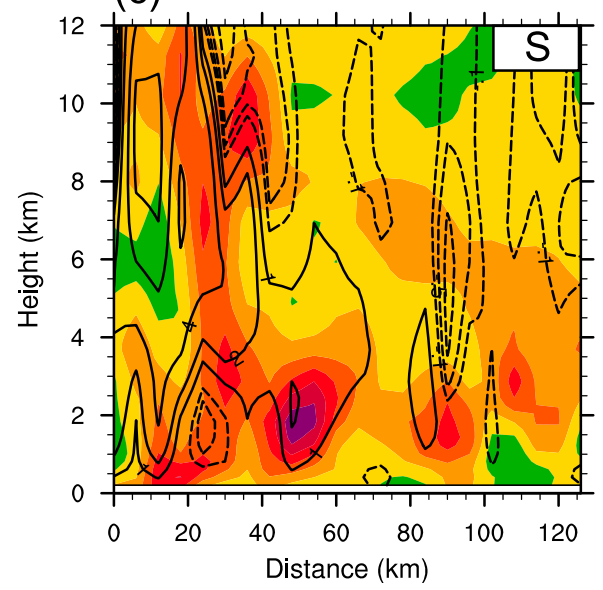

(b)

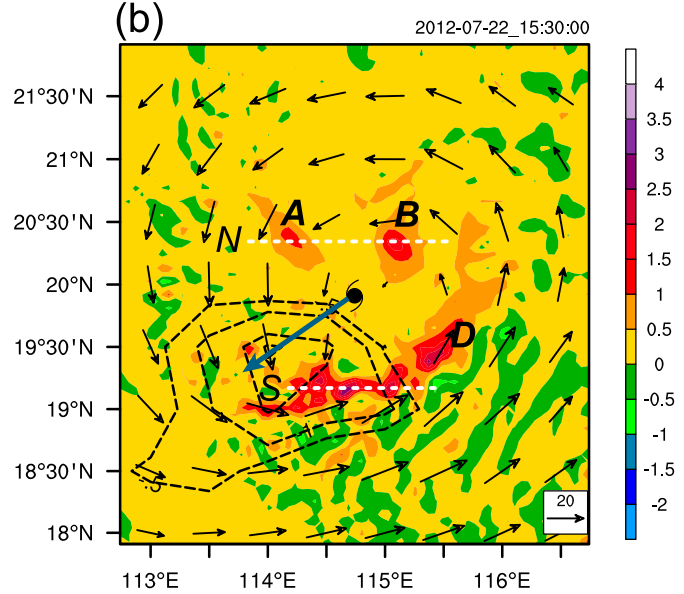

(d)

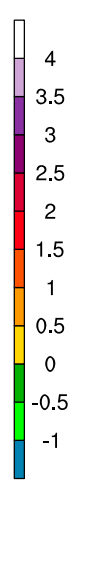

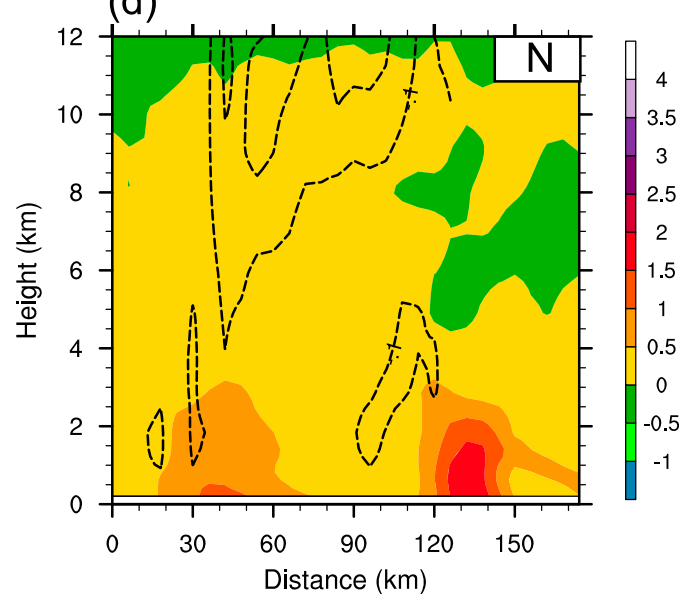

FIG. 4. (a) The simulated composite radar reflectivity (shading; $\mathrm{dBZ}$ ), the 850-hPa storm-relative winds (vectors; $\mathrm{m} \mathrm{s}^{-1}$ ), and the 850-hPa background horizontal convergence (dashed contours with values of $-2.0,-1.0,-0.5 \times 10^{-4} \mathrm{~s}^{-1}$ ) at 1530 UTC 22 Jul. (b) As in (a), except the shading represents 850-hPa relative vorticity (shading; $10^{-3} \mathrm{~s}^{-1}$ ). (c), (d) The vertical slices of relative vorticity (shading; $10^{-3} \mathrm{~s}^{-1}$ ) and vertical velocity (contours with values of $-2,-1,-0.5,-0.1,1,2,4,8$, $12 \mathrm{~m} \mathrm{~s}^{-1}$; negative values are dashed) along the southern (label S) and northern (label N) white line segment shown in (b). The blue thick arrows in (a) and (b) represent the 300-850-hPa environmental VWS $\left(5.3 \mathrm{~m} \mathrm{~s}^{-1}\right)$.

downshear CPS forms and develops in the convergence zone after the model spinup (Figs. 3a,b). As the convective activity in the CPS intensify, the convergence zone is in turn further enhanced (Figs. 3a,b). Meanwhile, the CPS also induces a positive vorticity band (PVB; $\sim 100-200 \mathrm{~km}$ in length) in the lower troposphere within the convergence zone (see Fig. 3e). Several mesovortices are split and detached from the downwind end of the PVB and are further advected downstream by the TC circulation (Figs. 3e,f).

Figures $4 \mathrm{c}$ and $4 \mathrm{~d}$ show the typical vertical structure of the PVB and the detached mesovortex at 1530 UTC 22 July. The PVB residing in the downshear-left quadrant exhibits structures of vortical hot towers (VHTs) at different stages, including during the developing stage (at $x=30 \mathrm{~km}$ in Fig. 4c) and the decaying stage (at $x=50$ and $90 \mathrm{~km}$ ). The latter stage is characterized by strong downdrafts $\left(>1 \mathrm{~m} \mathrm{~s}^{-1}\right)$ superimposed upon shallow vorticity structures. The developing VHT structure is associated with vigorous deep convection in the central area of the downshear convergence zone. Deep convection weakens as it propagates downstream owing to its own life cycle, and the associated VHT structure becomes shallower (not shown). This explains why the downstream part of the PVB is primarily confined to the lower troposphere $(<4 \mathrm{~km})$. Similarly, the detached mesovortices A and B remain shallow in the lower troposphere (Fig. 4d), akin to the decaying VHT within the PVB (Fig. 4c). Nevertheless, their superimposed downdrafts are generally weaker $\left(\sim 0.1 \mathrm{~m} \mathrm{~s}^{-1}\right)$ after they are further detached from the convergence zone and rotate cyclonically into the upshear flank 

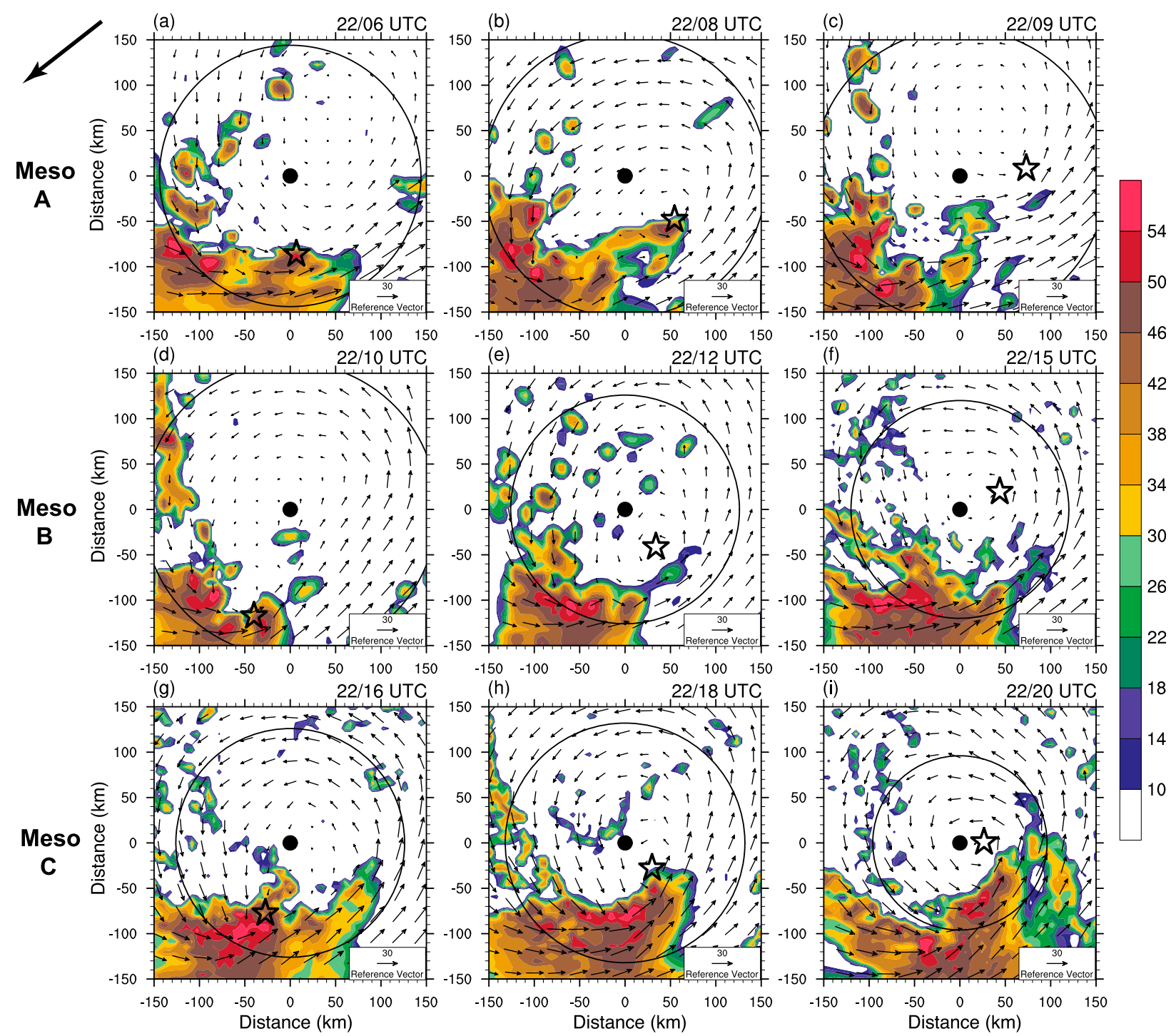

FIG. 5. Horizontal cross section of 850-hPa radar reflectivity (shading) and storm-relative winds at different times showing the evolution of mesovortices (a)-(c) A, (d)-(f) B, and (g)-(i) C. The black circle in each panel denotes the radius of maximum wind. The black dot (star) represents the TC center (the mesovortex center). The black arrow in the upper-left corner denotes the composite 300-850-hPa environmental VWS from 0600 to 2000 UTC $22 \mathrm{Jul}\left(\sim 5.2 \mathrm{~m} \mathrm{~s}^{-1}\right)$.

(Fig. 4b), wherein mesoscale subsidence $\left(0.1-0.5 \mathrm{~m} \mathrm{~s}^{-1}\right)$ prevails in the mid- to upper troposphere (Fig. 4d).

Figure 5 shows three mesovortices (i.e., A-C) that formed during RI onset. Mesovortex $\mathrm{C}$ behaves differently from mesovortices $\mathrm{A}$ and $\mathrm{B}$ in at least two aspects. First, mesovortex $\mathrm{C}$ is larger and stronger than either mesovortex A or B, as inferred from a rough estimation of the magnitude and radial extent of the associated cyclonic circulation. Second, the downshear CPS rotates cyclonically to the upshear flank following the movement of mesovortex C (Figs. 5g-i), rather than mesovortices A and B. Figure 6 shows the hourly tracks of these mesovortices based on the $850-\mathrm{hPa}$ relative vorticity field. Both mesovortices $\mathrm{A}$ and $\mathrm{B}$ rotate cyclonically around the TC center until they return to the downshear convergence zone, while mesovortex $\mathrm{C}$ spirals right into the TC center. The translational velocity ${ }^{2}$ of these mesovortices is $0.7-0.9$ times the velocity of local

\footnotetext{
${ }^{2}$ The translational speed of a mesovortex is estimated by tracking the $850-\mathrm{hPa}$ mesovortex centers at 1 -h interval. The mesovortex center refers to the vorticity centroid within a circle of radius $30 \mathrm{~km}$.
} 


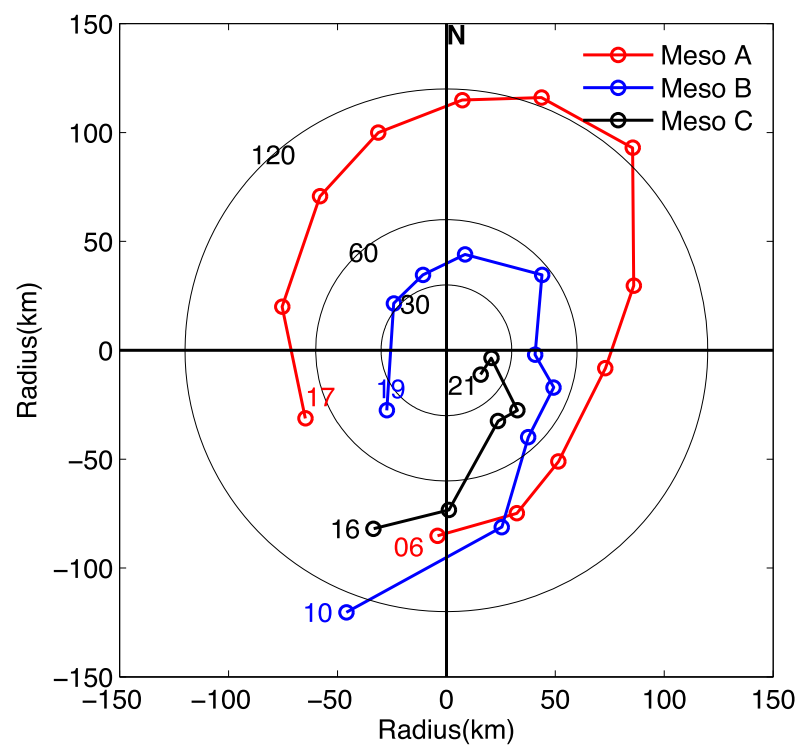

FIG. 6. Hourly tracks of the three mesovortices (A-C) in a stormrelative coordinate at the 850 -hPa pressure level. Color labels denote the beginning and ending hours (UTC) on 22 Jul 2012 of each mesovortex track.

azimuthal-mean tangential winds, similar to that reported by Montgomery et al. (2006). The average orbital radius decreases from mesovortex A to B to C (Fig. 6), similar to the contraction of the RMW during RI onset (Fig. 1b). We will show in section $4 \mathrm{~d}$ that shrinking of the orbital radius is closely connected to the downshear deflection of the TC center during downshear reformation.

To understand the different behavior of mesovortex $\mathrm{C}$, we show in Fig. 7 the hourly evolution of $900-\mathrm{hPa}$ relative vorticity and geopotential height. Before the formation of mesovortex $\mathrm{C}$, mesovortices $\mathrm{A}$ and $\mathrm{B}$ have their own local geopotential height minima (Figs. 7a-c). After 1600 UTC 22 July, mesovortex $\mathrm{C}$ forms in the downshear PVB with the lowest geopotential height at that level (Fig. 7d). It merges with the nearby convectively induced positive vorticity anomalies and its horizontal size subsequently increases (Figs. 7e,f). At 1900 UTC 22 July, mesovortex C becomes the dominant vorticity core in the lower troposphere and its central geopotential height minimum deepens by $\sim 700$ gpm in $3 \mathrm{~h}$ (Fig. 7f). Later, mesovortex C (i.e., the reformed inner vortex) gradually replaces the original TC center (Fig. 6), a process referred to as "downshear reformation" by Molinari et al. (2004, 2006). In the next section, we will analyze the dynamical processes and diagnose the mechanisms to understand how the reformed inner core grows upscale, develops upward, and resists the environmental VWS to undergo vertical alignment.

\section{Downshear reformation}

\section{a. Formation of the dominant inner vortex in the lower troposphere}

Results in Figs. 7d-f suggest that the dominant inner vortex forms as a consequence of the growth of mesovortex C. To examine the mechanisms responsible for the formation of the dominant inner vortex, we conduct a budget analysis for the vertical component of relative vorticity following Fang and Zhang (2011). The budget equation can be written as

$$
\begin{aligned}
\left.\frac{\partial \zeta}{\partial t}\right|_{\mathrm{SR}}= & -\left(\mathbf{V}_{h}-\mathbf{C}\right) \cdot \nabla_{h}(\zeta+f)-w \frac{\partial \zeta}{\partial z}-(\zeta+f) \nabla_{h} \cdot\left(\mathbf{V}_{h}-\mathbf{C}\right) \\
& -\left(\frac{\partial w}{\partial x} \frac{\partial v}{\partial z}-\frac{\partial w}{\partial y} \frac{\partial u}{\partial z}\right)+\frac{1}{\rho^{2}}\left(\frac{\partial \rho}{\partial x} \frac{\partial P}{\partial y}-\frac{\partial \rho}{\partial y} \frac{\partial P}{\partial x}\right)+\frac{\partial F_{y}}{\partial x}-\frac{\partial F_{x}}{\partial y},
\end{aligned}
$$

where $\zeta$ is the vertical relative vorticity, $\mathbf{V}_{h}$ is the horizontal wind vector, and $\mathbf{C}$ is the storm translational velocity vector based on the surface TC center. The subscript SR denotes that the budget terms in Eq. (3) are calculated in a reference frame moving with the simulated Typhoon Vicente. The terms on the right-hand side of Eq. (3) are the horizontal advection of absolute vorticity (HADV), the vertical advection of relative vorticity (VADV), stretching, tilting, solenoidal effects, and the horizontal curl of subgrid-scale mixing including surface friction, respectively. The solenoidal term is generally very small and contributes insignificantly to the net vorticity tendency (Montgomery et al. 2006). For simplicity, we calculate the vorticity budget at the 200-m height where the vertical advection and tilting terms are negligible, similar to the results of Fang and Zhang (2011).

Figures $8 \mathrm{a}-\mathrm{f}$ show the vorticity evolution at $200-\mathrm{m}$ height from 1750 to 1840 UTC 22 July, which is the key period for the formation of the inner vortex. From 1750 to 1800 UTC 22 July, the meso- $\beta$-scale positive vorticity anomaly (PVA) C2 merges with the PVA C1 downstream and grows in size. A similar merging process was also shown by Hendricks et al. (2004). The resultant 

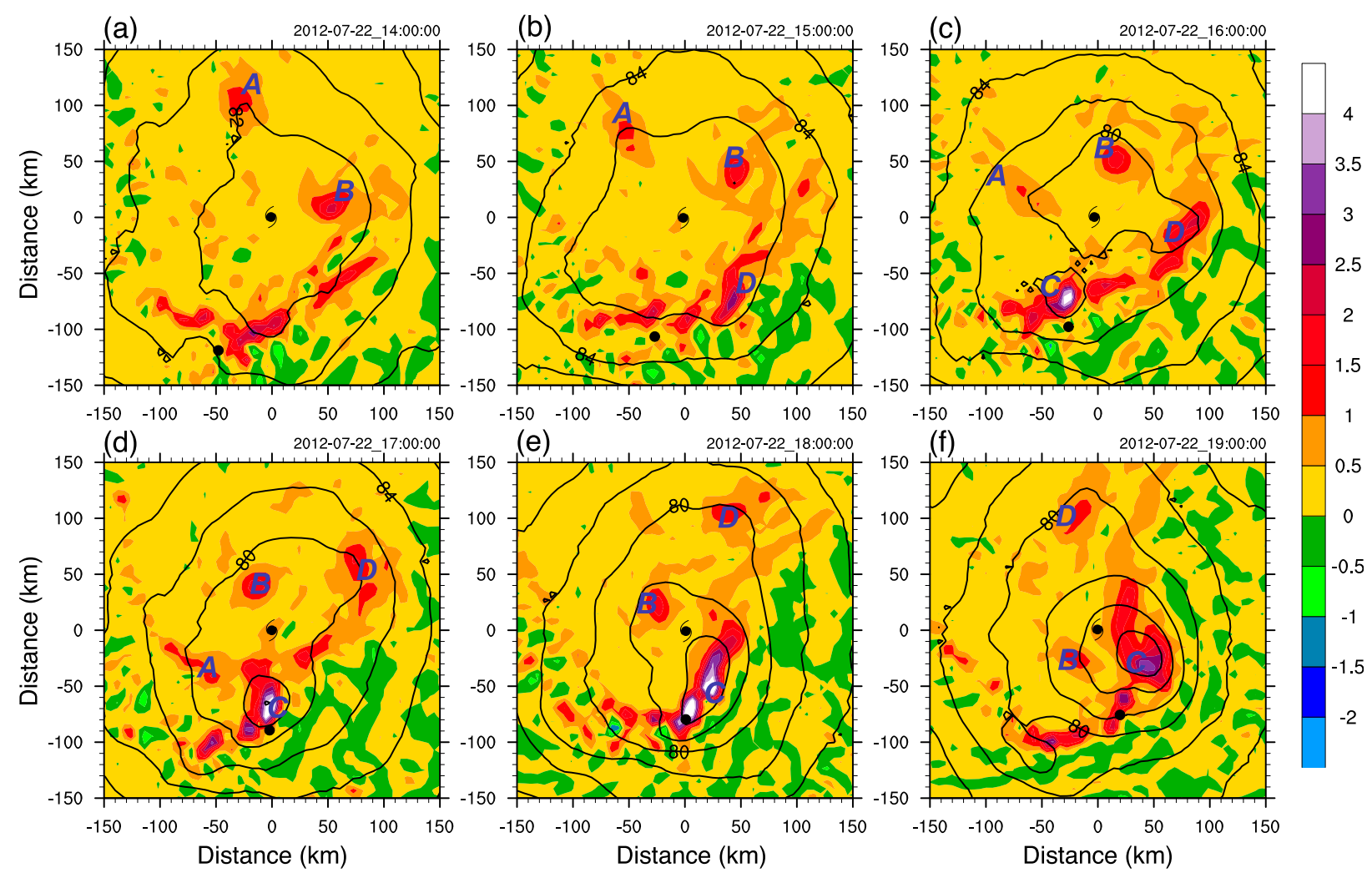

FIG. 7. Hourly evolution of $900-\mathrm{hPa}$ relative vorticity (shading; $10^{-3} \mathrm{~s}^{-1}$ ) and geopotential height (contoured every $2 \times 10^{2}$ gpm) from (a) 1400 to (f) 1900 UTC 22 Jul. The black hurricane symbol (dot) in each panel denotes the surface $(500 \mathrm{hPa}) \mathrm{TC}$ center. Labels A-D denote different mesovortices while the tracks of A, B, and C are shown in Fig. 6. Note that mesovortex D is weak and loosely organized and never dominates the vorticity asymmetries in $900 \mathrm{hPa}$, and thus its label $\mathrm{D}$ is an exception of chronological labeling.

vorticity of their aggregates (referred to as $\mathrm{C} 2$ herein) is enhanced and peaks at 1810 UTC 22 July, which is attributed primarily to the convectively induced stretching effect (Figs. 8h,i). At 1810 UTC 22 July, a newly developed convective cell, as inferred from the diabatic heating (Fig. 8c), emerges in the midst of $\mathrm{C} 2$ and $\mathrm{C} 3$, through which PVA C3 finally approaches C2 (Fig. 8c). Meanwhile, PVA C3 grows upscale and intensifies via merging with the meso- $\gamma$-scale vorticity anomaly induced by the convective cell (Figs. 8c,d). In contrast, PVA C2 enters into the upshear side and is devoid of diabatic heating after 1810 UTC 22 July. The associated stretching effect on PVA C2 gradually weakens as does its intensity (in terms of vorticity). After 1820 UTC 22 July, PVA C3 continues to intensify due to the imposed diabatic heating (Fig. 8e) and the resultant stretching effect (Fig. 8k). Ultimately, PVA C3 absorbs the weaker PVA C2 and evolves into a larger mesovortex C (i.e., the dominant inner vortex) in the lower troposphere (Figs. 8e,f). Note that during the 50-min period, the horizontal advection term simply acts to transport vorticity downstream and thus plays a circumstantial role in the upscale growth of mesovortex C. In addition, the subgrid-scale term contributes slightly to the enhancement of vorticity nearby the emerging/developing convection due to frictional convergence in the boundary layer, and the maximum value of $2.1 \times 10^{-6} \mathrm{~s}^{-2}$ is $\sim 12.7 \%$ of the peak magnitude of the stretching term (not shown).

From the above analysis, we conclude that successive moist convection in the downshear CPS contributes significantly to the formation of the reformed inner vortex in at least two aspects. First, the successive moist convection induces sufficient meso- $\gamma$-scale vorticity anomalies in the lower troposphere, which benefits the formation and ensuing upscale growth of PVAs via successive merger processes. Second, it further concentrates the existing downstream PVAs and the newly formed upstream PVAs into a larger and more dominant mesovortex $\mathrm{C}$ through the stretching effect.

\section{b. Timing of the downshear reformation}

A question arises as to why mesovortex $\mathrm{C}$, rather than the previous mesovortices $\mathrm{A}$ or $\mathrm{B}$, undergoes the 

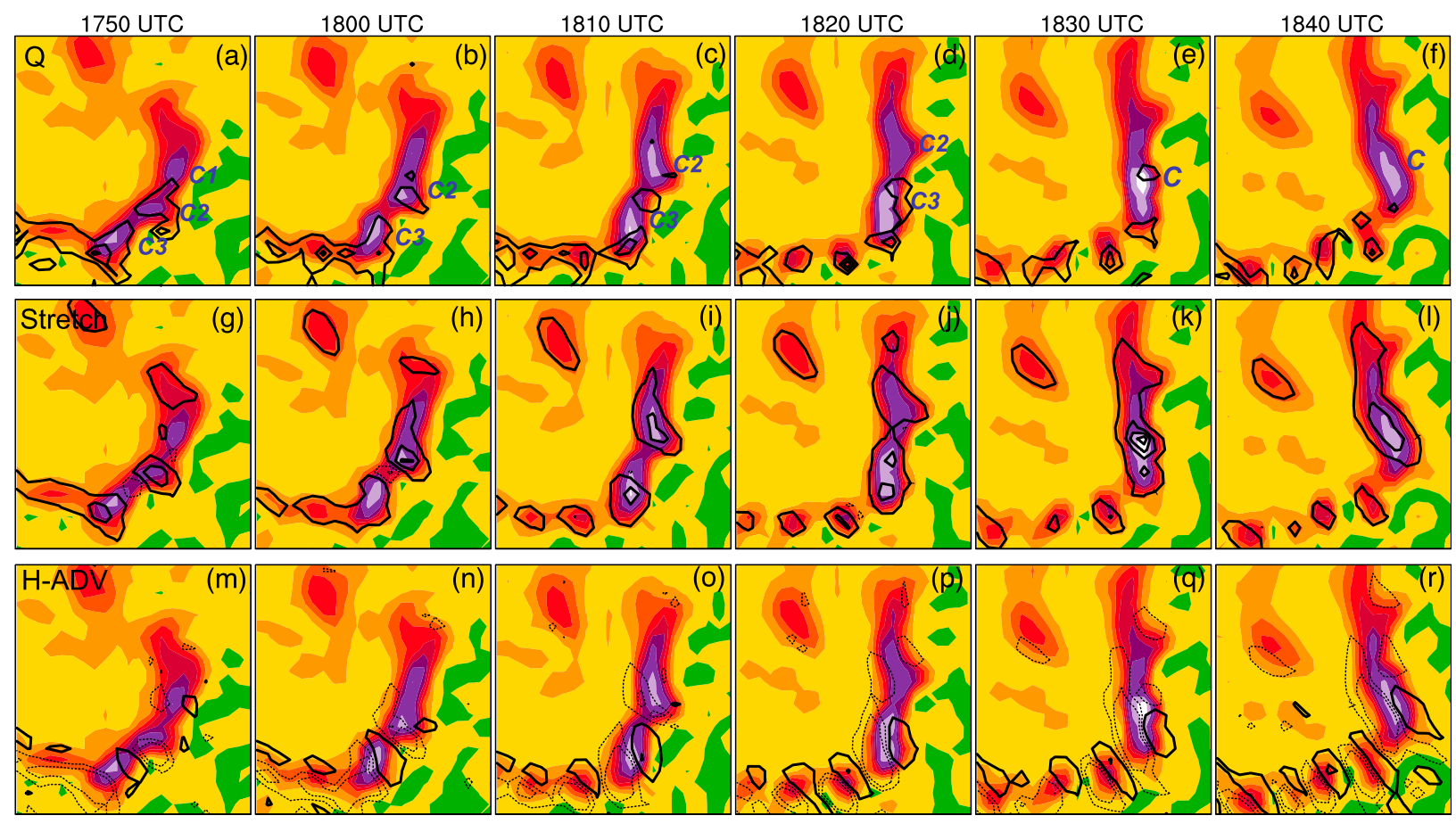

$$
\begin{array}{llllllllll|l|l|}
-1 & -0.5 & 0 & 0.5 & 1 & 1.5 & 2 & 2.5 & 3 & 4 & 5
\end{array}
$$

FIG. 8. (a)-(f) Evolution of relative vorticity at 200-m height (shading; $10^{-3} \mathrm{~s}^{-1}$ ) and diabatic heating at 300-m height (contours with values of $1,5 \times 10^{-3} \mathrm{~K} \mathrm{~s}^{-1}$ ) from 1750 to 1840 UTC 22 Jul every $10 \mathrm{~min}$. (g)-(l) As in (a)-(f), but for relative vorticity and stretching term (contours with values of $-1,1,5,9,13 \times 10^{-6} \mathrm{~s}^{-2}$; negative values are dashed) at 200-m height. (m)-(r) As in (a)-(f), but for relative vorticity and the horizontal advection term (contours with values of $-3,-1,1,5 \times 10^{-6} \mathrm{~s}^{-2}$; negative values are dashed) at 200-m height. The domain size of each panel is $1.2^{\circ} \times 1.2^{\circ}$.

downshear reformation; in other words, what determines the timing of the downshear reformation? Answering this question could help to clarify why only a few TCs in the sheared environment undergo downshear reformation. Given the importance of convective activity in the CPS to the downshear reformation, we show in Fig. 9 the time evolution of convective burst (CB) number in different shear-relative quadrants and also in the whole annulus within a radius of 50$150 \mathrm{~km}$ from the surface TC center. Following Chen and Gopalakrishnan (2015), a CB is defined when the maximum vertical velocity at a grid point in the column is greater than $3 \mathrm{~ms}^{-1}$. The lower bound radius of the annulus is selected because the RMW is generally larger than $50 \mathrm{~km}$ before 0200 UTC 23 July (Fig. 1b) and few CBs exist within the 50-km radius (not shown).

Before 2000 UTC 22 July, the CBs are located primarily in the downshear-right to downshear-left quadrants, within the CPS (Figs. 5 and 9). The number of CBs in the downshear-right quadrant gradually decreases after 0900 UTC 22 July, while the opposite trend is observed in the downshear-left quadrant, reflecting the cyclonic rotation of downshear CPS. The number of CBs in the downshear-left quadrant peaks during 1750-1810 UTC 22 July, which is the period that is key to the downshear reformation (Fig. 8). Accompanied with the occurrence of the peak number of CBs, the convective updrafts in the mid- and upper troposphere gradually achieve their maximum intensity at 1800 UTC 22 July (Fig. 10). Two episodes of extreme convective updrafts

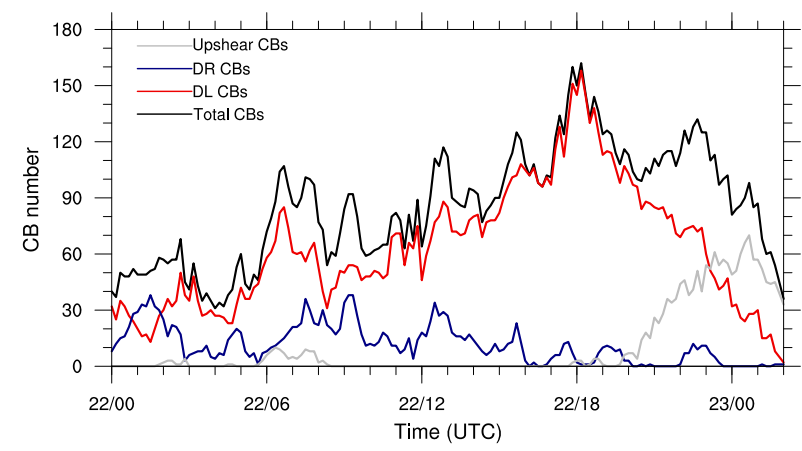

FIG. 9. Time evolution of CB number in the upshear side (gray), downshear-right quadrant (blue), downshear-left quadrant (red), and the whole azimuthal coverage (black) within the $r=50-150-\mathrm{km}$ annulus from the surface TC center. 


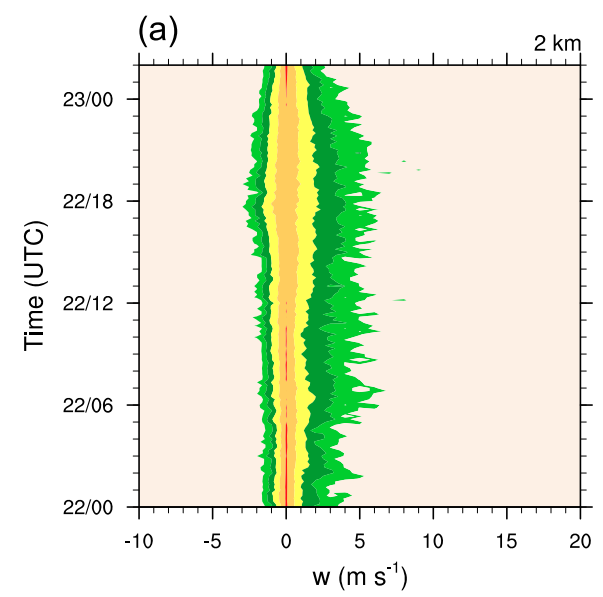

(b)

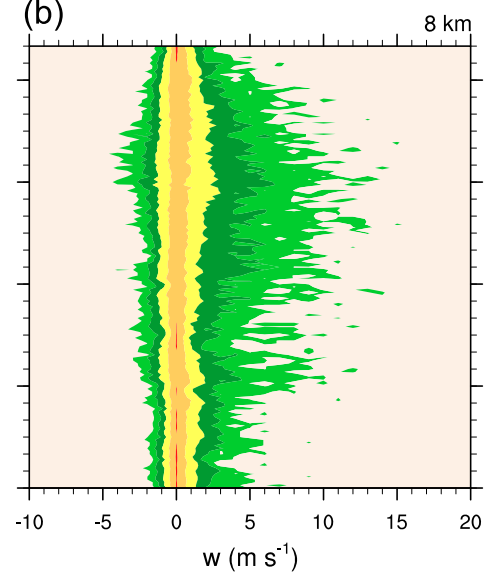

(c)

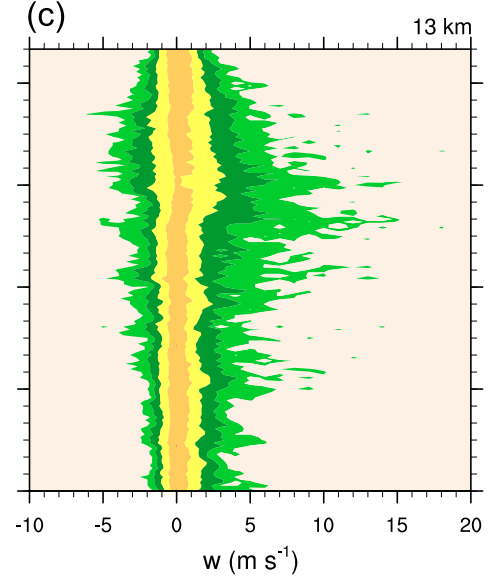

0

0.5

1

1.5

2

2.5

FIG. 10. Cumulative contour frequency distributions of vertical velocity $\left(\mathrm{m} \mathrm{s}^{-1}\right)$ within the $50-150-\mathrm{km}$ annulus as a function of time at (a) 2-, (b) 8-, and (c) 13-km heights. The frequency value shown here is calculated as $\log _{10}(n+1)$, where $n$ is the original frequency (number of occurrences).

$\left(\sim 15 \mathrm{~m} \mathrm{~s}^{-1}\right)$ at $13-\mathrm{km}$ height occur at 1600 and 1800 UTC 22 July, respectively. The first episode is related to the formation of mesovortex $\mathrm{C}$ (Fig. 6) and the second is concurrent with the time when mesovortex $\mathrm{C}$ grows into the dominant, reformed inner vortex (Fig. 7e). After 1810 UTC 22 July, the number of CBs in the downshear-left quadrant decreases steadily as the CPS (or CBs) further rotates into the upshear flank (Fig. 9). The rotation of CPS is closely related to the evolution of vortex tilt, as will be shown in the following subsections.

To examine the possible mechanism responsible for the enhanced convective activity in the downshear-left quadrant, and hence the timing of downshear reformation, Fig. 11 shows the distribution of surface latent heat flux (LHX) at six time points before RI occurrence. Two contours of vertical velocity are highlighted to represent the convective bursts ( $w=3 \mathrm{~m} \mathrm{~s}^{-1}$ at $5-\mathrm{km}$ height) and mesoscale downdrafts ( $w=-0.1 \mathrm{~m} \mathrm{~s}^{-1}$ at 1.5 -km height) that flush low-entropy air into the inflow boundary layer. The area with $w>3 \mathrm{~m} \mathrm{~s}^{-1}$ is a good indicator of CBs, as it generally overlaps areas of strong convection with elevated radar reflectivity, as inferred from a comparison of Figs. 11 and 5. Sensible heat flux is relatively small compared with LHX (15\%-20\% of LHX) and thus is not shown. Prior to 1800 UTC 22 July, LHX on the leftof-shear semicircle is $\sim 200 \mathrm{~W} \mathrm{~m}^{-2}$ larger than its counterpart on the right-of-shear semicircle. In fact, the wavenumber-1 pattern of LHX distribution has appeared since the beginning of model integration, when the convective precipitation has not formed yet (not shown). Thus, the wavenumber-1 pattern is primarily due to the superposition of low-level southwesterly monsoon flow-counteraligned with VWS—on the TC circulation, which induces a positive surface wind anomaly in the left-of-shear semicircle. The mesoscale downdrafts downwind of CBs may further help to enhance the LHX $\left(>600 \mathrm{~W} \mathrm{~m}^{-2}\right)$ in the left-of-shear semicircle by flushing low-entropy air into the boundary layer (e.g., Figs. 11a-c).

A remarkable phenomenon is that the mean location of CBs (or CPS) gradually rotates from downshear to downshear left prior to 1800 UTC 22 July (Figs. 11a-d). Meanwhile, the elevated LHX in the downshear-left quadrant gradually amplifies over time as the TC intensifies, which is a favorable factor to explain the increasing trend in the number of CBs during 0900-1800 UTC 22 July. In addition, we also examine the boundary layer convergence near the RMW in the downshear-left quadrant. It seems to play a secondary role, given the fact that the gradual enhancement of boundary layer convergence occurs synchronous with, rather than leading, the increase in the number of CBs (not shown). These results indicate that the thermodynamic favorability of the gradual amplification of LHX in the left-ofshear semicircle help to promote more vigorous CBs as the CPS rotates into the downshear-left quadrant. Therefore, it plays a prominent role in the formation of the dominant inner vortex and, thus, has an impact on the timing of downshear reformation.

\section{c. Vertical development and alignment of the reformed inner vortex}

After the onset of downshear reformation at 1900 UTC 22 July, the reformed inner vortex continues to grow in both size and strength via axisymmetrization of the upstream PVB remnant and the returned prior 

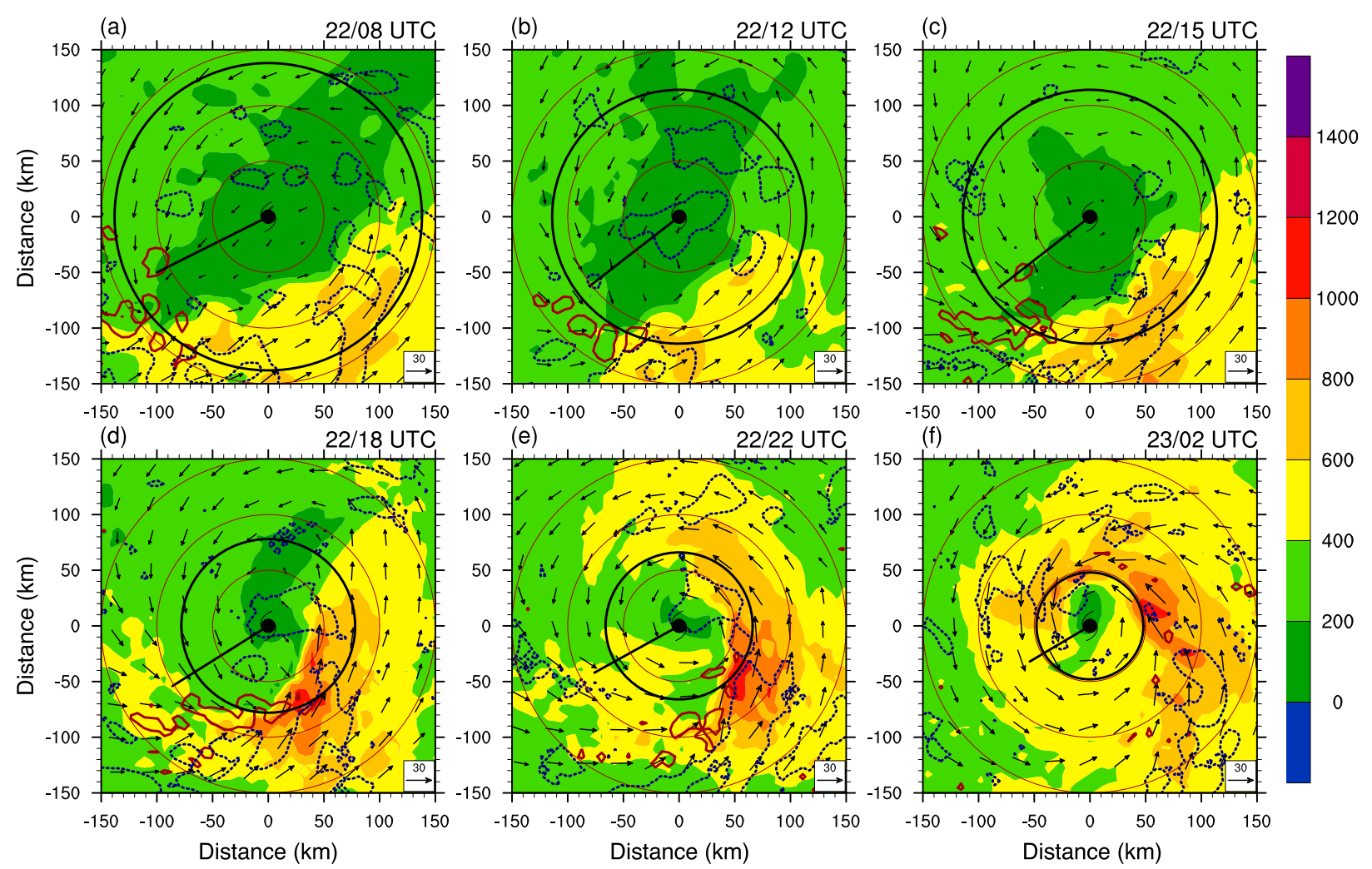

FIG. 11. Distributions of surface latent heat flux (shading) and horizontal wind vectors at the lowest model level at six different time points. The dashed blue (solid red) curves are the -0.1 (3) $\mathrm{m} \mathrm{s}^{-1}$ contours of vertical velocity at the height of 1.5 (5) $\mathrm{km}$. The hurricane symbol represents the surface TC center. The solid black line starting from the TC center in each panel represents environmental VWS.

mesovortices (Figs. 12d-f), leading to a more spiraling downshear CPS (Figs. 5i and 12a-c). Then, the CPS that is coupled with the midlevel vortex rotates cyclonically and enters the upshear flank after 2100 UTC 22 July (not shown), a process reported in many recent studies (e.g., Onderlinde and Nolan 2014, 2016; Rogers et al. 2016; Zawislak et al. 2016; Munsell et al. 2017). Meanwhile, the reformed inner vortex develops vertically and undergoes vertical alignment during downshear reformation.

At 2000 UTC 22 July, the reformed inner vortex tilts downshear left in a clockwise manner ${ }^{3}$ from $z=2$ to $8 \mathrm{~km}$ (Fig. 12d), similar to the inner-core structure of the sheared TCs observed by airborne Doppler radars (Marks et al. 1992; Roux and Marks 1996; Reasor and Eastin 2012). The vertical structure of relative vorticity and vertical velocity along the spirally tilted axis at 2000

\footnotetext{
${ }^{3}$ The center of the reformed inner vortex at each vertical level is represented by the vorticity centroid, calculated within a circle of radius $30 \mathrm{~km}$ in the second model domain with a horizontal resolution of $6 \mathrm{~km}$. See Eq. (1), noting that the pressure deficit is replaced by relative vorticity.
}

UTC 22 July indicate that the reformed inner vortex, which spans between the $60-$ and $120-\mathrm{km}$ radii, extends upward to 8-km height (Fig. 12j). The vortex is adjacent to a downtilt strong deep convective cell characterized by strong updrafts $\left(>4 \mathrm{~m} \mathrm{~s}^{-1}\right)$ in the midtroposphere and vorticity maxima in the mid- to upper troposphere. The center of the reformed inner vortex at $6-\mathrm{km}$ height is along the flank of the vorticity maxima, suggesting that the downtilt convection contributes to vertical development of the reformed inner vortex. In addition, the tilt of the reformed inner vortex in the 2-6-km layer is as large as $33 \mathrm{~km}$. These findings are in contrast to the results in Nguyen and Molinari (2015), who found that the reformed inner vortex was initially shallow $(<3 \mathrm{~km})$ and almost vertically aligned (see their Fig. 10). We hypothesize that their Fig. 10 showed the vertical structure of a nascent convective cell rather than the reformed inner vortex, based on the following reasons. First, the diameter of their "reformed inner vortex (mesovortex)" was only $\sim 5 \mathrm{~km}$. Second, the shallow "reformed inner vortex" extended vertically to the top of troposphere in $\sim 30$ min (i.e., the typical convective overturning time) whereas the vertical development of the reformed inner vortex in our case takes several hours. Third, the 

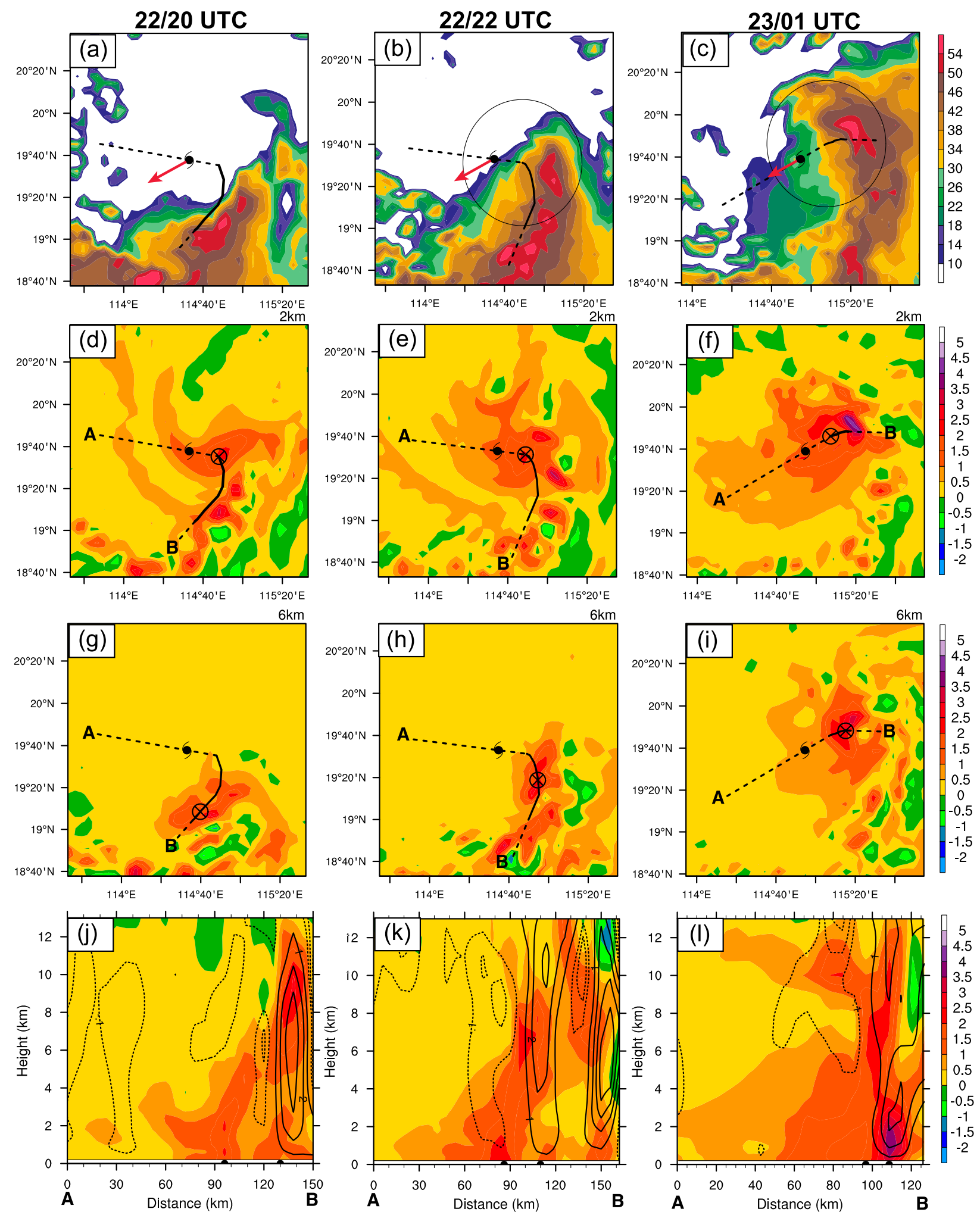

FIG. 12. (a)-(c) Composite radar reflectivity (dBZ), (d)-(f) 2-km relative vorticity $\left(10^{-3} \mathrm{~s}^{-1}\right)$, and (g)-(i) 6-km relative vorticity $\left(10^{-3} \mathrm{~s}^{-1}\right)$ at $2000 \mathrm{UTC} 22 \mathrm{Jul}, 2200 \mathrm{UTC} 22 \mathrm{Jul}$, and $0100 \mathrm{UTC} 23 \mathrm{Jul}$, respectively. (j)-(l) The vertical cross section of relative vorticity (shading; $10^{-3} \mathrm{~s}^{-1}$ ) and vertical velocity (contoured at $-1,-0.5,-0.1,1,2,3,4,8 \mathrm{~m} \mathrm{~s}^{-1}$; negative values are dashed) at the same three times. The location of the vertical cross section is shown as the black line $\mathrm{AB}$ (including a curved solid line with two straight dashed lines at 
diameter of the reformed inner vortex was approximately $50-60 \mathrm{~km}$ in their smoothed field (see their Fig. 15), suggesting that the vertical structure of the small mesovortex in their Fig. 10 is not representative of the reformed inner vortex.

By 2200 UTC 22 July, the reformed inner vortex develops vertically upward to $10-\mathrm{km}$ height (Fig. 12k). Mesoscale subsidence $\left(>0.1 \mathrm{~m} \mathrm{~s}^{-1}\right)$ prevails over the center of the tilted, reformed inner vortex while strong convective updraft $\left(>4 \mathrm{~m} \mathrm{~s}^{-1}\right)$ appears on the downtilt side. The tilt in the $2-6-\mathrm{km}$ layer decreases to $23 \mathrm{~km}$ at this time. Three hours later, the reformed inner vortex extends farther to $12-\mathrm{km}$ height and grows substantially in its horizontal size in the mid- to lower troposphere (Figs. 12l) compared with that at 2000 UTC 22 July (Fig. 12j). The inner vortex at 6-km height has precessed into the upshear flank relative to the low-level inner vortex (Fig. 12i) and the tilt between 2- and 6-km heights further decreases to $12 \mathrm{~km}$ (Fig. 121). This suggests that differential vorticity advection by environmental VWS might play a role in reducing the tilt of the reformed inner vortex when it tilts toward the upshear side.

To test this hypothesis and explore the physical mechanisms responsible for the bottom-up development and vertical alignment of the reformed inner vortex, we perform the relative vorticity budget analysis [cf. Eq. (3)] again. Here, $\mathbf{C}$ represents the translational speed of the reformed inner vortex at 2-km height. Figure 13 displays the different budget terms in Eq. (3) at 2-8-km heights during the period between 2100 UTC 22 July and 0100 UTC 23 July, when the midlevel inner vortex stays in the upshear flank. These budget terms are averaged within a circle of $50-\mathrm{km}$ radius centered on the reformed inner vortex at $2-\mathrm{km}$ height, and this area encloses the vorticity core structure of the reformed inner vortex and the coupled CPS (see Figs. 12b,c).

During the 4-h budget period, the area-averaged relative vorticity increases throughout the $2-8-\mathrm{km}$ height range. An evaluation of the budget terms on the right-hand side of Eq. (3) indicates that the stretching term only remains positive beneath 4-km height. This shallow-layer convergence of the cyclonic vorticity is likely due to the tilted structure of the reformed inner vortex (e.g., Fig. 12k). Above 4-km height, the negative stretching term is due to the area-averaged divergence in the midtroposphere (not

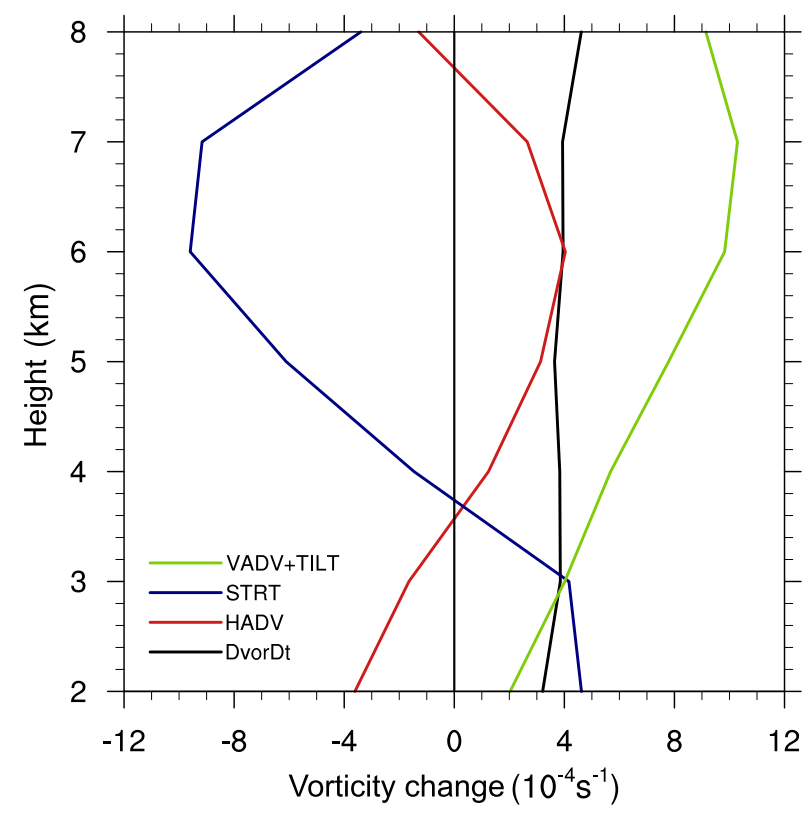

FIG. 13. Vertical profile of vorticity budget results $\left(10^{-4} \mathrm{~s}^{-1}\right)$ averaged with the 50-km-radius circle during 2100 UTC 22 Jul-0100 UTC $23 \mathrm{Jul}$ at 10-min interval. The individual budget terms shown include area-averaged vorticity change (black) on the lhs of Eq. (3), the HADV term (red), stretching term (blue), and the sum of VADV and tilting terms (green).

shown), although there exists some CBs within the budget circle. In contrast, the HADV term contributes to the cyclonic vortex enhancement primarily in the midtroposphere $(>4 \mathrm{~km})$. Although previous studies argued that the differential vorticity advection by the vertically sheared environmental flow contributes to the vertical alignment of a tilted vortex and thus enhances the midlevel vorticity over the low-level vortex center, the results here indicates that this effect, as is primarily included in the HADV term, is too weak to overwhelm the negative role of stretching term in the midtroposphere.

Instead, the dominant term that contributes to the enhancement of the inner vortex throughout the 2-8-km height range is the sum of the area-averaged tilting and VADV terms, the high value of which is well correlated with the CBs in the rotating CPS. That is, the convective updrafts tilt the outward-pointing horizontal vorticity filaments and thus induce positive vorticity inside the budget circle that is concurrently advected upward.

both ends) in (d)-(f). The curved solid line in (a)-(c) represents the tilt of the reformed inner vortex in the 2-8-km layer at 1-km interval. The hurricane symbol in (a)-(i) represents the surface TC center. The black crossed circle in (d)-(i) represents the 2- and 6-km centers of the reformed inner vortex, respectively. The two black dots from left to right in (j)-(l) are the 2- and 6-km centers of the reformed inner vortex, respectively. The red arrows in (a)-(c) represent the 300-850-hPa environmental VWS. The black circles centered on 2-km center of reformed inner vortex in (b) and (c) represent the vorticity budget area in Fig. 13. 

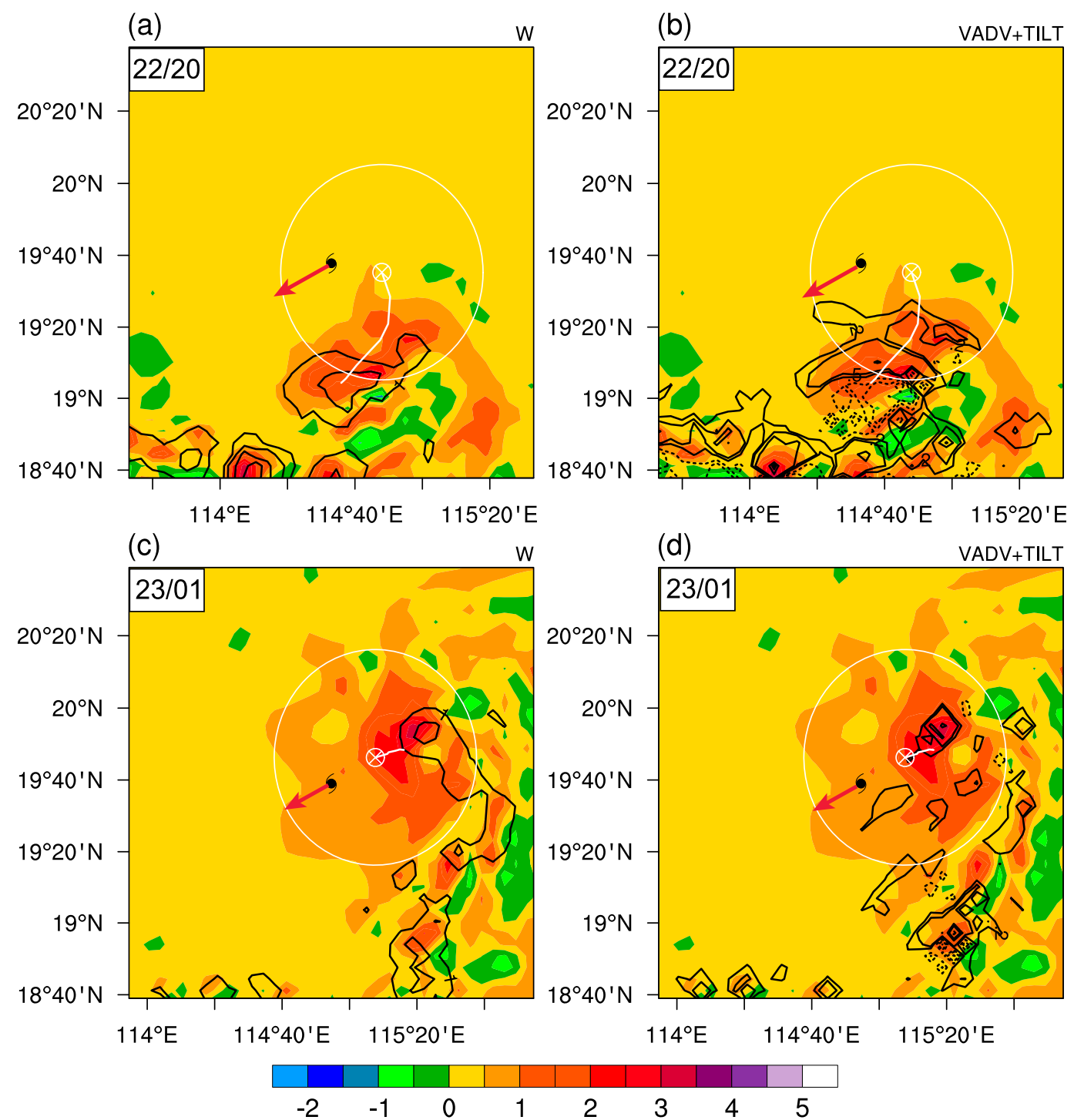

FIG. 14. (top) The 6-km relative vorticity (shading; $10^{-3} \mathrm{~s}^{-1}$ ) overlaid with (a) vertical velocity (contours with values of $1,3,6$, and $9 \mathrm{~m} \mathrm{~s}^{-1}$ ) and (b) the sum of VADV and tilting terms (contours with values of $-1,-0.5,0.2,0.5$, $1.5 \times 10^{-6} \mathrm{~s}^{-2}$; negative values are dashed) on the rhs of Eq. (3) at $2000 \mathrm{UTC} 22 \mathrm{Jul}$. (c),(d) As in (a) and (b), respectively, but at 0100 UTC $23 \mathrm{Jul}$. The hurricane symbol represents the surface TC center. The red arrows in (a)-(c) represent the 300-850-hPa environmental VWS. The white spiral line in each panel represents 2-8-km tilt, and the large white circle marks the 50-km-radius budget circle that is centered on the 2-km center of the reformed inner vortex (white crossed circle). Similar circles are also shown in Figs. 12b and 12c.

Figure 14 exemplifies this process, as the sum of tilting and VADV terms at 6-km height is maximized radially inward of the intense convective updrafts $\left(>3 \mathrm{~m} \mathrm{~s}^{-1}\right)$ at both 2200 UTC 22 July and 0100 UTC 23 July. Here we consider the combined effect of VADV and tilting terms because both terms are correlated to the convective updrafts and CBs in the downtilt direction of the reformed inner core (Figs. 12k,l), and the two terms counteract each other as indicated by their contrary gradient with height (i.e., one's growth at the expense of the other's decrease; not shown), which is consistent with previous studies (e.g., Fang and Zhang 2010). In addition, the primary sources of horizontal vorticity filaments are most likely the environmental VWS and the vertical shear of tangential winds.

In summary, the vorticity budget results suggest that the continuous CBs in the CPS play a dominant role in the vertical development of the tilted reformed inner vortex by tilting the horizontal vorticity filaments and transporting the induced positive vertical vorticity upward, 
which effectively overwhelms the negative role of the midlevel divergence (or stretching term). In comparison, the HADV term that includes the differential vorticity advection by the vertically sheared environmental flow plays a secondary role in the midlevel vorticity enhancement. However, it is important to advect the enhanced midlevel vortex toward the low-level inner vortex and thus contributes to vertical alignment of the reformed inner vortex at the end of the downshear reformation. The findings regarding the potential influence of differential vorticity advection by the vertically sheared environmental flow on vertical alignment are in line with the hypothesis proposed in the observational studies for Hurricane Earl (Stevenson et al. 2014; Rogers et al. 2015) and in ensemble simulations of Hurricane Edouard (Munsell et al. 2017).

\section{d. Vertical alignment of the TC-scale vortex}

Nguyen and Molinari (2015) argued that the large tilt of the parent vortex was substituted by the small tilt of the reformed inner vortex after the completion of the downshear reformation, leading to vertical alignment. Here, we examine the detailed evolution of the TC-scale (or parent) vortex tilt in different stages of the downshear reformation. To better illustrate the vertical alignment of the TC-scale vortex in the sheared environment, two parameters (TC vortex tilt and inner-core shear) are defined for the following discussion. The TC vortex tilt is defined as the difference between the 900and 500-hPa geopotential height centroids, while the inner-core shear is calculated as the difference in horizontal winds averaged within a $300-\mathrm{km}$ radius from the 700-hPa geopotential height centroid between 500 and $900 \mathrm{hPa}$. These definitions are consistent with those of Rappin and Nolan (2012) except that we use the geopotential height centroid instead of the Ertel potential vorticity centroid to define the TC vortex center. It has been found that the geopotential height centroid is a better representation of the vortex center for weak TCs with embedded strong mesoscale vorticity anomalies (Nguyen et al. 2014). In comparison, the environmental VWS in this study is defined as the shear vector averaged within the 300-800-km annulus between two given pressure levels as used earlier. In the following discussion, the shear-relative quadrant is based on the environmental VWS vector.

We will first briefly discuss the tilt and VWS evolution prior to the onset of downshear reformation. The midlevel TC vortex is advected downshear of the low-level TC vortex due to the differential advection by the environmental shear flow from the beginning of the simulation (Fig. 15), and the TC vortex tilt reaches a maximum of $240 \mathrm{~km}$ at 1500 UTC 21 July (Fig. 15b). Then, the tilt oscillates around $200 \mathrm{~km}$ until 0300
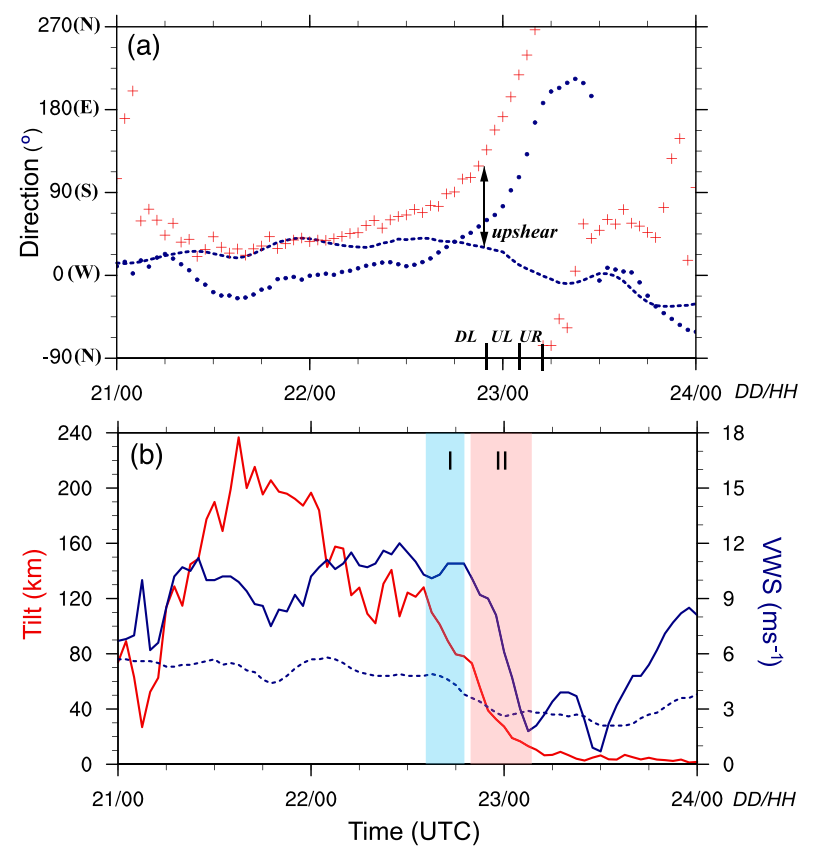

FIG. 15. Time evolution of (a) directions and (b) magnitudes of 500-900-hPa inner-core shear [blue dots in (a), blue solid line in (b)], environmental VWS (blue dashed line), and vortex tilt [red plus signs in (a), red solid line in (b)]. The direction in (a) is defined as the angle rotating anticlockwise from due west. The black arrow marks the time when the midlevel TC vortex precesses into the upshear flank. The blue and pink shadings in (b) denote stage I and stage II of vertical alignment, respectively. The shear-relative quadrants are indicated [downshear left (DL), upshear left (UL), and upshear right (UR)] with thick black segments along the time axis in (a).

UTC 22 July, followed by a significant reduction as the midlevel TC vortex precesses into the downshear-left quadrant (Fig. 15a). At 0600 UTC 22 July, the tilt reaches a quasi-stationary value of $\sim 120 \mathrm{~km}$ and persists until 1500 UTC 22 July. Interestingly, while the direction of the environmental VWS is almost unchanged during the period, the inner-core shear vector rotates cyclonically following the tilt vector. The direction of inner-core shear is about $60^{\circ}-70^{\circ}$ to the right of the tilt vector (Fig. 15a). This is because the inner-core shear includes both the environmental VWS and the mesoscale shear induced by the tilted TC vortex; the direction of the latter shear is fixed at $90^{\circ}$ to the right of the vortex tilt vector (Davis and Bosart 2006).

Between 1500 UTC 22 July and 0200 UTC 23 July, the TC vortex tilt decreases significantly under the influence of downshear reformation. According to the variation in the inner-core shear, two stages of vertical alignment that lead to a vertically coherent TC vortex are identified. In stage I (i.e., from 1500 UTC to 1900 UTC 22 July), the TC vortex tilt decreases from 120 to $80 \mathrm{~km}$ and the inner-core shear remains at $10-11 \mathrm{~m} \mathrm{~s}^{-1}$ (Fig. 15b). In contrast, in stage II (i.e., from 
2000 UTC 22 July to 0200 UTC 23 July), both the innercore shear and the TC vortex tilt decreases rapidly after the midlevel TC vortex enters the upshear flank. The different evolutions of the inner-core shear and the TC vortex tilt during the two stages of vertical alignment suggest different underlying mechanisms. The precession rate of the midlevel TC vortex is only $\sim 8^{\circ} \mathrm{h}^{-1}$ in stage I while it increases to $\sim 20^{\circ} \mathrm{h}^{-1}$ in stage II (Fig. 15a), suggesting an enhanced interaction between the mid- and low-level TC circulations in stage II.

Figure 16 shows the hourly trajectories of the low- and midlevel TC centers during RI onset. Clearly, the vertical alignment in stage I is primarily related to the deflection of the low-level TC center to approach the midlevel TC center or CPS. As mesovortex $\mathrm{C}$ deepens and grows into the reformed inner vortex during stage I (Figs. 7 and 8), it is strong enough to deflect the low-level TC center southward owing to its large weight in determining the geopotential height centroid (i.e., the TC-scale center), leading to a reduction in TC vortex tilt. Since this reformed inner vortex has a horizontal scale (diameter) of $\sim 50 \mathrm{~km}$ (Fig. 7f), it does not significantly affect the inner-core shear, which is defined as the wind shear averaged within a circle of $300-\mathrm{km}$ radius from the lowlevel TC center (Fig. 15b).

In stage II, both the tilt and inner-core shear decrease dramatically after the midlevel TC vortex enters the upshear flank by 2100 UTC 22 July (Fig. 15b). The vertical alignment in stage II is associated with the rapid precession $\left(\sim 20^{\circ} \mathrm{h}^{-1}\right)$ of the midlevel TC vortex (Figs. 15a and 16). The trajectory of the low-level TC center closely follows that of the reformed inner vortex during stage II, while the midlevel TC center generally overlaps the center of the reformed inner vortex (not shown). Therefore, the rapid precession illustrated in Figs. 15a and 16 actually reflects the precession of the midlevel inner vortex (see the discussion in section 4c). At 0200 UTC 23 July, the magnitude of the inner-core shear decreases to a minimum $\left(\sim 2 \mathrm{~m} \mathrm{~s}^{-1}\right)$ and becomes comparable to the large-scale VWS. This is primarily due to the distinct reduction in mesoscale shear for a vertically coherent reformed inner vortex of substantial size. Note that both the tilt of the parent (TC) vortex and the reformed inner vortex are less than $15 \mathrm{~km}$ at this time (Figs. 12i and 15b), suggesting that the parent TC vortex is successfully replaced by the reformed inner vortex at the end of downshear reformation.

\section{Summary and conclusions}

In this study, we have examined the key inner-core processes related to the downshear reformation that effectively resists the moderate environmental VWS

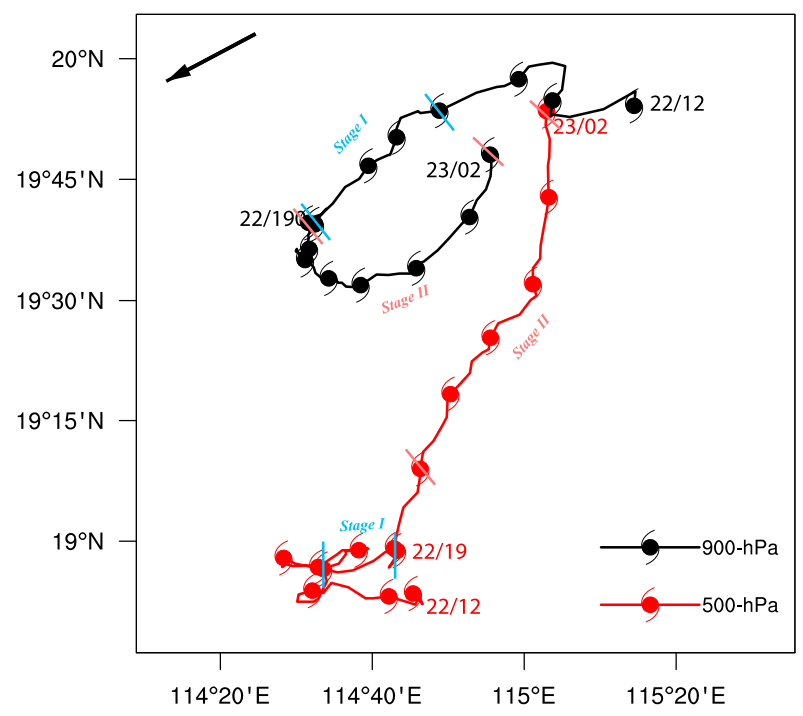

FIG. 16. Hourly trajectories of 500- (red) and 900-hPa (black) TC centers from 1200 UTC 22 Jul to 0200 UTC 23 Jul. The two stages of vertical alignment are labeled. The thick black arrow represents the direction of composite 500-900-hPa environmental VWS within this period. The pair of blue (orange) short lines delimit the stage I (II) of vertical alignment.

during RI onset of Typhoon Vicente (2012), using simulation results described in Part I. It is found that a downshear convergence zone forms shortly after Vicente enters the South China Sea. Two factors are responsible for the formation of this zone: (i) background convergence between the southwesterly monsoon flows and the northerly winds in the western part of the TC circulation and (ii) enhanced differential vorticity advection by thermal wind (i.e., environmental VWS) due to the gradual intensification of the TC primary circulation, which strengthens the low-level convergence in the downshear flank. In the downshear convergence zone, a convective precipitation shield (CPS) forms and convection further enhances the low-level convergence. The convective activity in the CPS induces a positive vorticity band (PVB) in the lower troposphere, from which multiple mesovortices are split, advected downstream, and detached from the downshear convergence zone. The last, strongest mesovortex behaves differently from previous mesovortices, and it wraps directly into the smaller radii of the TC circulation with downshear CPS. This mesovortex grows successively in horizontal size and strength via repeated mergers with nearby positive vorticity anomalies and becomes the dominant vorticity core (i.e., the reformed inner vortex) in the lower troposphere, thus triggering the downshear reformation.

After the onset of downshear reformation, the reformed inner vortex, which extends to a height of $8 \mathrm{~km}$, tilts clockwise with height to the downshear-left quadrant, 
(a)

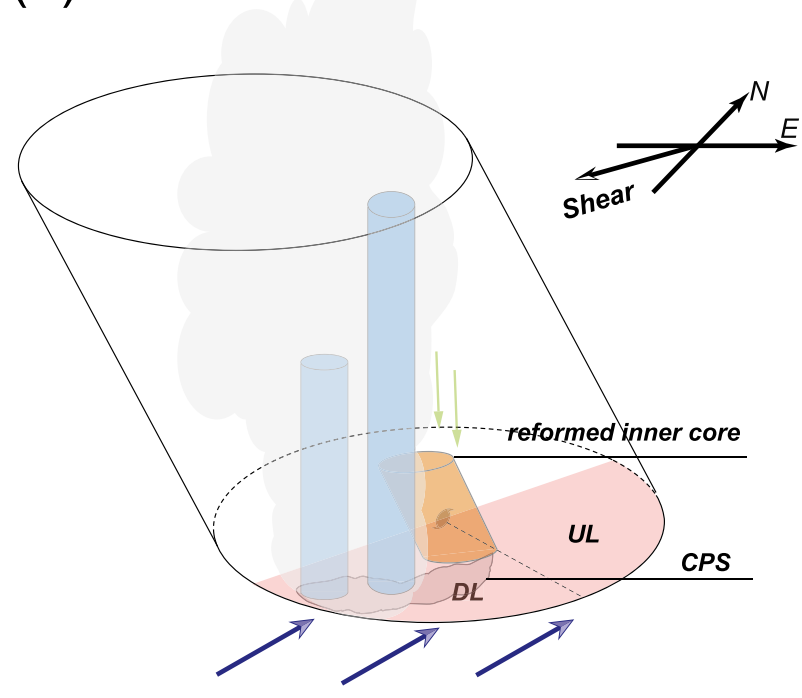

stage I (b)

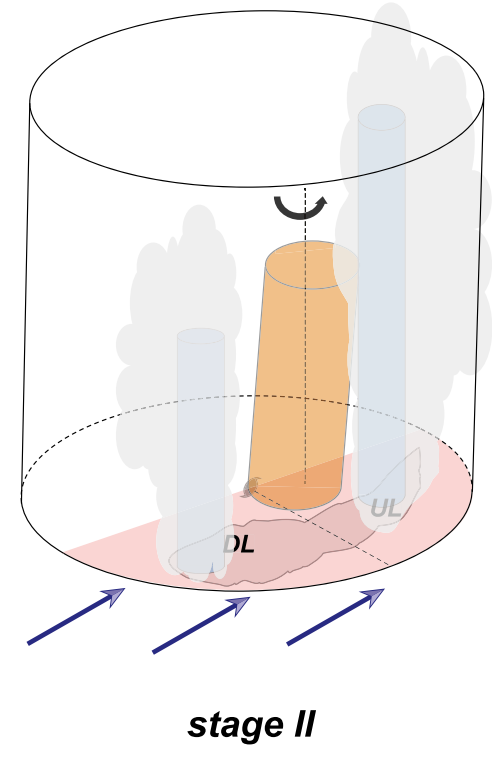

FIG. 17. The conceptual model of stages (a) I and (b) II of vertical alignment related to the downshear reformation. The dark gray shading on the surface denotes the CPS, and the light gray plumes above represent the convection or CBs in the CPS. The orange (blue) cylinder represents the reformed inner vortex (different stages of VHT induced by the CBs in the CPS). The larger tilted cylinder represents the broader, parent vortex. The blue arrows denote the surface southwesterly monsoonal flow, and the green arrows in (a) represent the mesoscale subsidence over the reformed inner vortex. The pink shading denotes the enhanced surface latent heat fluxes in the left-of-shear semicircle due to the configuration of counteraligned surface monsoonal flow and the environmental VWS. The labels DL and UL represent the downshear-left and upshear-left quadrants, respectively. For a better visualization of the reformed inner vortex in (b), the convective clouds in the CPS that block the view of inner vortex is not drawn.

instead of being vertically coherent as suggested by Nguyen and Molinari (2015). Benefiting from downtilt deep convection, the reformed inner vortex gradually develops upward by tilting the horizontal vorticity into vertical and meanwhile transporting the vertical vorticity upward, which overwhelms the substantial, negative stretching effect in the midtroposphere. In comparison, the horizontal absolute vorticity advection plays a relatively small role in enhancing the midlevel vorticity but is important to vertically align the tilted inner vortex by advecting the midlevel inner vortex toward the low-level inner vortex, suggesting the potential role of differential vorticity advection by environmental VWS.

The downshear reformation process impacts the vertical alignment of the TC-scale parent vortex via two stages (Fig. 17). In the first stage, the formation of a shallow and tilted reformed inner vortex, with a geopotential height minimum in the lower troposphere, helps deflect the low-level TC-scale center southward to approach the midlevel TC center, thus reducing the tilt of the parent TC vortex. In the second stage (i.e., after the onset of downshear reformation), the reformed inner vortex becomes broader, deeper, and more intense. The vertical alignment of the reformed inner vortex contributes to the vertical alignment of the TC-scale parent vortex, as the rapid precession between the lower- and midlevel centers of the parent TC vortex is similar to that of the reformed inner vortex. In our simulation, we do not find evidence for axisymmetrization of the parent TC vortex by the reformed inner vortex, as proposed by Molinari et al. $(2004,2006)$. This can be ascribed to the fact that it is difficult to separate the parent vortex from the reformed inner vortex in a real-case simulation.

Our results also suggest that the timing of downshear reformation is determined by the $\mathrm{CB}$ activity in the downshear CPS. In particular, two consecutive episodes of the most intense CBs in the downshear-left quadrant contribute directly to the formation of the last, strongest mesovortex and its upscale growth into the reformed inner vortex. The southwesterly monsoon flow, in a direction opposite to the environmental VWS, induces elevated surface heat flux in the left-of-shear semicircle that gradually amplifies with the intensifying TC circulation. This favorable thermodynamic condition help to promote 
more vigorous $\mathrm{CBs}$ as the midlevel $\mathrm{TC}$ vortex coupled with CPS rotates from downshear to downshear left, thus having an impact on the timing of downshear reformation.

Besides the inner-core dynamical processes, the longlasting, extreme RI of Vicente is also ascribed to the decrease in environmental VWS during RI onset, which is attributed primarily to two processes. First, a weak inverted upper-tropospheric trough (UTT) propagated away from the TC center and the superimposed upper-level northeasterly over the low-level TC center dwindled as discussed in Part I. Second, the poleward convective ridging associated with the rotating CPS (see Fig. 14b in Part I) during downshear reformation also helped reduce the northeasterly environmental VWS. This suggests that attention should be paid to the propagation of the UTT (Shieh et al. 2013) and to the interaction between the downshear CPS and the UTT for the RI forecast. Few studies have focused on the effects of the time-evolving environmental VWS associated with the complex UTT-TC interactions on TC RI; this should be investigated in future studies.

Note that although many RI TCs are associated with the inward spiral of downshear CPS and vertical alignment prior to RI occurrence (see discussions in section 1), few RI cases experience downshear reformation scenario. Downshear reformation seems more likely to occur for tropical storms embedded in relatively strong environmental VWS ( $>10 \mathrm{~m} \mathrm{~s}^{-1}$ in the 200-850-hPa layer) prior to RI occurrence (Molinari et al. 2006; Davis et al. 2008; Nguyen and Molinari 2015), as the case for Vicente studied here. Therefore, the present results and mechanisms related to the RI case involving downshear reformation should not be overgeneralized to all RI cases that show an inward spiral of downshear CPS and vertical alignment before RI.

Finally, we would mention that since 1981, there are only two RI cases fitting the South China Sea RI flow pattern SU1, ${ }^{4}$ namely Typhoon Vicente (2012) and Typhoon Prapiroon (2006); the latter was briefly discussed by Chen et al. (2015). The two cases share many similarities in their RI occurrence. First, the westward translation decelerates before a sudden northward track deflection. A similar track deflection or looping motion was reported by Molinari et al. (2004). Second, the environmental VWS decreases rapidly during the track

\footnotetext{
${ }^{4} \mathrm{SU} 1$ is the only lower-tropospheric RI flow pattern during the summer monsoon over the South China Sea based on the all RI cases in the SCS during 1981-2011 (Chen et al. 2015). It is characterized by the provision of southwesterly monsoon flow and a westward shift of the subtropical high. The environmental VWS is stronger in this period than during the premonsoon or postmonsoon periods.
}

deflection. Some questions arise as to whether Typhoon Prapiroon (2006) also undergoes downshear reformation or whether the downshear reformation is an indispensable component of SU1 RI cases. This is a question worthy of further investigation. In addition, what is the occurrence frequency of downshear reformation for RI TCs in the monsoon trough over the western North Pacific and South China Sea, and are the RI mechanisms discussed in this study applicable to other RI cases? These are topics to be addressed in our future studies.

Acknowledgments. This study has been supported by the National Foundational Research "973" Program of China (2015CB452805 and 2013CB430103); the Natural Science Foundation of China Grants 41730960, 41605033, 41475046, 41130964, 41375068, and 41322032; and by the NSF Grant AGS-1326524. The authors benefited from discussions with Fuqing Zhang, Robert F. Rogers, Michael M. Bell, Leon T. Nguyen, Zhe-Min Tan, Jian-Feng Gu, and Qizhi Chen.

\section{REFERENCES}

Black, M. L., J. F. Gamache, F. D. Marks, C. E. Samsury, and H. E. Willoughby, 2002: Eastern Pacific Hurricanes Jimena of 1991 and Olivia of 1994: The effect of vertical shear on structure and intensity. Mon. Wea. Rev., 130, 2291-2312, https://doi.org/ 10.1175/1520-0493(2002)130<2291:EPHJOA > 2.0.CO;2.

Bracken, W. E., and L. F. Bosart, 2000: The role of synoptic-scale flow during tropical cyclogenesis over the North Atlantic Ocean. Mon. Wea. Rev., 128, 353-376, https://doi.org/10.1175/ 1520-0493(2000)128<0353:TROSSF > 2.0.CO;2.

Chen, H., and S. G. Gopalakrishnan, 2015: A study on the asymmetric rapid intensification of Hurricane Earl (2010) using the HWRF system. J. Atmos. Sci., 72, 531-550, https://doi.org/ 10.1175/JAS-D-14-0097.1.

Chen, X., Y. Wang, and K. Zhao, 2015: Synoptic flow patterns and large-scale characteristics associated with rapidly intensifying tropical cyclones in the South China Sea. Mon. Wea. Rev., 143, 64-87, https://doi.org/10.1175/MWR-D-13-00338.1.

,$--\longrightarrow$, and $\mathrm{D}$. Wu, 2017: A numerical study on rapid intensification of Typhoon Vicente (2012) in the South China Sea. Part I: Verification of simulation, storm-scale evolution, and environmental contribution. Mon. Wea. Rev., 145, 877-898, https://doi.org/10.1175/MWR-D-16-0147.1.

Cram, T. A., J. Persing, M. T. Montgomery, and S. A. Braun, 2007: A Lagrangian trajectory view on transport and mixing processes between the eye, eyewall, and environment using a highresolution simulation of Hurricane Bonnie (1998). J. Atmos. Sci., 64, 1835-1856, https://doi.org/10.1175/JAS3921.1.

Davis, C. A., and L. F. Bosart, 2006: The formation of Hurricane Humberto (2001): The importance of extra-tropical precursors. Quart. J. Roy. Meteor. Soc., 132, 2055-2085, https:// doi.org/10.1256/qj.05.42.

, S. C. Jones, and M. Riemer, 2008: Hurricane vortex dynamics during Atlantic extratropical transition. J. Atmos. Sci., 65, 714-736, https://doi.org/10.1175/2007JAS2488.1. 
DeHart, J. C., R. A. Houze, and R. F. Rogers, 2014: Quadrant distribution of tropical cyclone inner-core kinematics in relation to environmental shear. J. Atmos. Sci., 71, 2713-2732, https://doi.org/10.1175/JAS-D-13-0298.1.

DeMaria, M., 1996: The effect of vertical shear on tropical cyclone intensity change. J. Atmos. Sci., 53, 2076-2088, https://doi.org/ 10.1175/1520-0469(1996)053<2076:TEOVSO > 2.0.CO;2.

_ C. R. Sampson, J. A. Knaff, and K. D. Musgrave, 2014: Is tropical cyclone intensity guidance improving? Bull. Amer. Meteor. Soc., 95, 387-398, https://doi.org/10.1175/BAMS-D-12-00240.1.

Emanuel, K. A., 1986: An air-sea interaction theory for tropical cyclones. Part I: Steady-state maintenance. J. Atmos. Sci. 43, 585-605, https:// doi.org/10.1175/1520-0469(1986)043<0585:AASITF>2.0.CO;2.

_ 1988: The maximum intensity of hurricanes. J. Atmos. Sci., 45, 1143-1155, https://doi.org/10.1175/1520-0469(1988)045<1143: $\mathrm{TMIOH}>2.0 . \mathrm{CO} ; 2$.

Fang, J., and F. Zhang, 2010: Initial development and genesis of Hurricane Dolly (2008). J. Atmos. Sci., 67, 655-672, https:// doi.org/10.1175/2009JAS3115.1.

- , and - 2011: Evolution of multiscale vortices in the development of Hurricane Dolly (2008). J. Atmos. Sci., 68 , 103-122, https://doi.org/10.1175/2010JAS3522.1.

Fischer, M. S., B. H. Tang, and K. L. Corbosiero, 2017: Assessing the influence of upper-tropospheric troughs on tropical cyclone intensification rates after genesis. Mon. Wea. Rev., 145, 1295-1313, https://doi.org/10.1175/MWR-D-16-0275.1.

Flatau, M., W. H. Schubert, and D. E. Stevens, 1994: The role of baroclinic processes in tropical cyclone motion: The influence of vertical tilt. J. Atmos. Sci., 51, 2589-2601, https://doi.org/ 10.1175/1520-0469(1994)051<2589:TROBPI > 2.0.CO;2.

Frank, W. M., and E. A. Ritchie, 2001: Effects of vertical wind shear on the intensity and structure of numerically simulated hurricanes. Mon. Wea. Rev., 129, 2249-2269, https://doi.org/ 10.1175/1520-0493(2001)129<2249:EOVWSO>2.0.CO;2.

Ge, X., T. Li, and M. Peng, 2013: Effects of vertical shears and midlevel dry air on tropical cyclone developments. J. Atmos. Sci., 70, 3859-3875, https://doi.org/10.1175/JAS-D-13-066.1.

Gray, W. M., 1968: Global view of the origin of tropical disturbances and storms. Mon. Wea. Rev., 96, 669-700, https://doi.org/ 10.1175/1520-0493(1968)096<0669:GVOTOO > 2.0.CO;2.

Gu, J.-F., Z.-M. Tan, and X. Qiu, 2015: Effects of vertical wind shear on inner-core thermodynamics of an idealized simulated tropical cyclone. J. Atmos. Sci., 72, 511-530, https://doi.org/ 10.1175/JAS-D-14-0050.1.

Hendricks, E. A., M. T. Montgomery, and C. A. Davis, 2004: The role of "vortical" hot towers in the formation of Tropical Cyclone Diana (1984). J. Atmos. Sci., 61, 1209-1232, https:// doi.org/10.1175/1520-0469(2004)061<1209:TROVHT>2.0.CO;2.

Jones, S. C., 1995: The evolution of vortices in vertical shear. I: Initially barotropic vortices. Quart. J. Roy. Meteor. Soc., 121, 821-851, https://doi.org/10.1002/qj.49712152406.

Kaplan, J., and M. DeMaria, 2003: Large-scale characteristics of rapidly intensifying tropical cyclones in the North Atlantic basin. Wea. Forecasting, 18, 1093-1108, https://doi.org/ 10.1175/1520-0434(2003)018<1093:LCORIT >2.0.CO;2.

,-- , and J. A. Knaff, 2010: A revised tropical cyclone rapid intensification index for the Atlantic and eastern North Pacific basins. Wea. Forecasting, 25, 220-241, https://doi.org/10.1175/ 2009WAF2222280.1.

Marks, F. D., R. A. Houze, and J. F. Gamache, 1992: Dual-aircraft investigation of the inner core of Hurricane Norbert. Part I: Kinematic structure. J. Atmos. Sci., 49, 919-942, https:// doi.org/10.1175/1520-0469(1992)049<0919:DAIOTI>2.0.CO;2.
Molinari, J., and D. Vollaro, 2010: Rapid intensification of a sheared tropical storm. Mon. Wea. Rev., 138, 3869-3885, https://doi.org/10.1175/2010MWR3378.1.

,-- , and K. L. Corbosiero, 2004: Tropical cyclone formation in a sheared environment: A case study. J. Atmos. Sci., 61, 2493-2509, https://doi.org/10.1175/JAS3291.1.

—, P. Dodge, D. Vollaro, K. L. Corbosiero, and F. Marks, 2006: Mesoscale aspects of the downshear reformation of a tropical cyclone. J. Atmos. Sci., 63, 341-354, https://doi.org/10.1175/ JAS3591.1.

Montgomery, M. T., M. E. Nicholls, T. A. Cram, and A. B. Saunders, 2006: A vortical hot tower route to tropical cyclogenesis. J. Atmos. Sci., 63, 355-386, https://doi.org/10.1175/ JAS3604.1.

Munsell, E. B., F. Zhang, J. A. Sippel, S. A. Braun, and Y. Weng, 2017: Dynamics and predictability of the intensification of Hurricane Edouard (2014). J. Atmos. Sci., 74, 573-595, https:// doi.org/10.1175/JAS-D-16-0018.1.

Nguyen, L. T., and J. Molinari, 2015: Simulation of the downshear reformation of a tropical cyclone. J. Atmos. Sci., 72, 45294551, https://doi.org/10.1175/JAS-D-15-0036.1.

,-- , and D. Thomas, 2014: Evaluation of tropical cyclone center identification methods in numerical models. Mon. Wea. Rev., 142 4326-4339, https://doi.org/10.1175/MWR-D-14-00044.1.

Nolan, D. S., Y. Moon, and D. P. Stern, 2007: Tropical cyclone intensification from asymmetric convection: Energetics and efficiency. J. Atmos. Sci., 64, 3377-3405, https://doi.org/ 10.1175/JAS3988.1.

Onderlinde, M. J., and D. S. Nolan, 2014: Environmental helicity and its effects on development and intensification of tropical cyclones. J. Atmos. Sci., 71, 4308-4320, https://doi.org/10.1175/ JAS-D-14-0085.1.

$\longrightarrow$, and —, 2016: Tropical cyclone-relative environmental helicity and the pathways to intensification in shear. J. Atmos. Sci., 73, 869-890, https://doi.org/10.1175/JAS-D-15-0261.1.

Pendergrass, A. G., and H. E. Willoughby, 2009: Diabatically induced secondary flows in tropical cyclones. Part I: Quasisteady forcing. Mon. Wea. Rev., 137, 805-821, https://doi.org/ 10.1175/2008MWR2657.1.

Rappaport, E. N., J.-G. Jiing, C. W. Landsea, S. T. Murillo, and J. L. Franklin, 2012: The joint hurricane test bed: Its first decade of tropical cyclone research-to-operations activities reviewed. Bull. Amer. Meteor. Soc., 93, 371-380, https://doi.org/10.1175/ BAMS-D-11-00037.1.

Rappin, E. D., and D. S. Nolan, 2012: The effect of vertical shear orientation on tropical cyclogenesis. Quart. J. Roy. Meteor. Soc., 138, 1035-1054, https://doi.org/10.1002/qj.977.

Reasor, P. D., and M. D. Eastin, 2012: Rapidly intensifying Hurricane Guillermo (1997). Part II: Resilience in shear. Mon. Wea. Rev., 140, 425-444, https://doi.org/10.1175/ MWR-D-11-00080.1.

—, M. T. Montgomery, and L. D. Grasso, 2004: A new look at the problem of tropical cyclones in vertical shear flow: Vortex resiliency. J. Atmos. Sci., 61, 3-22, https://doi.org/10.1175/ 1520-0469(2004)061<0003:ANLATP>2.0.CO;2.

— M. D. Eastin, and J. F. Gamache, 2009: Rapidly intensifying Hurricane Guillermo (1997). Part I: Low-wavenumber structure and evolution. Mon. Wea. Rev., 137, 603-631, https://doi.org/10.1175/2008MWR2487.1.

, R. Rogers, and S. Lorsolo, 2013: Environmental flow impacts on tropical cyclone structure diagnosed from airborne Doppler radar composites. Mon. Wea. Rev., 141, 2949-2969, https:// doi.org/10.1175/MWR-D-12-00334.1. 
Riemer, M., M. T. Montgomery, and M. E. Nicholls, 2010: A new paradigm for intensity modification of tropical cyclones: Thermodynamic impact of vertical wind shear on the inflow layer. Atmos. Chem. Phys., 10, 3163-3188, https://doi.org/ 10.5194/acp-10-3163-2010.

Rogers, R., P. Reasor, and S. Lorsolo, 2013: Airborne Doppler observations of the inner-core structural differences between intensifying and steady-state tropical cyclones. Mon. Wea. Rev., 141, 2970-2991, https://doi.org/10.1175/MWR-D-12-00357.1.

,-- , and J. A. Zhang, 2015: Multiscale structure and evolution of Hurricane Earl (2010) during rapid intensification. Mon. Wea. Rev., 143, 536-562, https://doi.org/10.1175/MWRD-14-00175.1.

_ , J. A. Zhang, J. Zawislak, H. Jiang, G. R. Alvey, E. J. Zipser, and S. N. Stevenson, 2016: Observations of the structure and evolution of Hurricane Edouard (2014) during intensity change. Part II: Kinematic structure and the distribution of deep convection. Mon. Wea. Rev., 144, 3355-3376, https:// doi.org/10.1175/MWR-D-16-0017.1.

Roux, F., and F. D. Marks, 1996: Extended velocity track display (EVTD): An improved processing method for Doppler radar observations of tropical cyclones. J. Atmos. Oceanic Technol., 13, 875-899, https://doi.org/10.1175/ 1520-0426(1996)013<0875:EVTDAI > 2.0.CO;2.

Schubert, W. H., and J. J. Hack, 1982: Inertial stability and tropical cyclone development. J. Atmos. Sci., 39, 1687-1697, https://doi. org/10.1175/1520-0469(1982)039<1687:ISATCD>2.0.CO;2.

Shapiro, L. J., and H. E. Willoughby, 1982: The response of balanced hurricanes to local sources of heat and momentum. J. Atmos. Sci., 39, 378-394, https://doi.org/10.1175/ 1520-0469(1982)039<0378:TROBHT>2.0.CO;2.

Shieh, O. H., M. Fiorino, M. E. Kucas, and B. Wang, 2013: Extreme rapid intensification of Typhoon Vicente (2012) in the South China Sea. Wea. Forecasting, 28, 1578-1587, https://doi.org/ 10.1175/WAF-D-13-00076.1.

Shu, S., J. Ming, and P. Chi, 2012: Large-scale characteristics and probability of rapidly intensifying tropical cyclones in the western North Pacific basin. Wea. Forecasting, 27, 411-423, https://doi.org/10.1175/WAF-D-11-00042.1.

Simpson, R. H., and H. Riehl, 1958: Mid-tropospheric ventilation as a constraint on hurricane development and maintenance. Proc. Tech. Conf. on Hurricanes, Miami, FL, Amer. Meteor. Soc., D4.1-D4.10.

Stevenson, S. N., K. L. Corbosiero, and J. Molinari, 2014: The convective evolution and rapid intensification of Hurricane Earl (2010). Mon. Wea. Rev., 142, 4364-4380, https://doi.org/ 10.1175/MWR-D-14-00078.1.

Susca-Lopata, G., J. Zawislak, E. J. Zipser, and R. F. Rogers, 2015: The role of observed environmental conditions and precipitation evolution in the rapid intensification of Hurricane Earl (2010). Mon. Wea. Rev., 143, 2207-2223, https://doi.org/ 10.1175/MWR-D-14-00283.1.
Tang, B., and K. Emanuel, 2010: Midlevel ventilation's constraint on tropical cyclone intensity. J. Atmos. Sci., 67, 1817-1830, https://doi.org/10.1175/2010JAS3318.1.

Tory, K. J., M. T. Montgomery, N. E. Davidson, and J. D. Kepert, 2006: Prediction and diagnosis of tropical cyclone formation in an NWP system. Part II: A diagnosis of Tropical Cyclone Chris formation. J. Atmos. Sci., 63, 3091-3113, https:// doi.org/10.1175/JAS3765.1.

Vigh, J. L., and W. H. Schubert, 2009: Rapid development of the tropical cyclone warm core. J. Atmos. Sci., 66, 3335-3350, https://doi.org/10.1175/2009JAS3092.1.

Wang, Y., and G. J. Holland, 1996: Tropical cyclone motion and evolution in vertical shear. J. Atmos. Sci., 53, 3313-3332, https:// doi.org/10.1175/1520-0469(1996)053<3313:TCMAEI>2.0.CO;2.

__ Y. Y. Rao, Z.-M. Tan, and D. Schönemann, 2015: A statistical analysis of the effects of vertical wind shear on tropical cyclone intensity change over the western North Pacific. Mon. Wea. Rev., 143, 3434-3453, https://doi.org/10.1175/ MWR-D-15-0049.1.

Wong, M. L. M., and J. C. L. Chan, 2004: Tropical cyclone intensity in vertical wind shear. J. Atmos. Sci., 61, 1859-1876, https:// doi.org/10.1175/1520-0469(2004)061<1859:TCIIVW>2.0.CO;2.

$\mathrm{Wu}, \mathrm{L}$., and S. A. Braun, 2004: Effects of environmentally induced asymmetries on hurricane intensity: A numerical study. J. Atmos. Sci., 61, 3065-3081, https://doi.org/10.1175/ JAS-3343.1.

$\mathrm{Xu}$, Y., and Y. Wang, 2013: On the initial development of asymmetric vertical motion and horizontal relative flow in a mature tropical cyclone embedded in environmental vertical shear. J. Atmos. Sci., 70, 3471-3491, https://doi.org/10.1175/ JAS-D-12-0335.1.

Zawislak, J., H. Jiang, G. R. Alvey, E. J. Zipser, R. F. Rogers, J. A. Zhang, and S. N. Stevenson, 2016: Observations of the structure and evolution of Hurricane Edouard (2014) during intensity change. Part I: Relationship between the thermodynamic structure and precipitation. Mon. Wea. Rev., 144, 33333354, https://doi.org/10.1175/MWR-D-16-0018.1.

Zeng, Z., Y. Wang, and C.-C. Wu, 2007: Environmental dynamical control of tropical cyclone intensity-An observational study. Mon. Wea. Rev., 135, 38-59, https://doi.org/10.1175/ MWR3278.1.

— L. Chen, and Y. Wang, 2008: An observational study of environmental dynamical control of tropical cyclone intensity in the Atlantic. Mon. Wea. Rev., 136, 3307-3322, https://doi.org/ 10.1175/2008MWR2388.1.

Zhang, D.-L., and C. Q. Kieu, 2006: Potential vorticity diagnosis of a simulated hurricane. Part II: Quasi-balanced contributions to forced secondary circulations. J. Atmos. Sci., 63, 2898-2914, https://doi.org/10.1175/JAS3790.1.

Zhang, F., and D. Tao, 2013: Effects of vertical wind shear on the predictability of tropical cyclones. J. Atmos. Sci., 70, 975-983, https://doi.org/10.1175/JAS-D-12-0133.1. 